\title{
RADIATIVE FORCING: CLIMATE POLICY TO BREAK THE LOGJAM IN ENVIRONMENTAL LAW
}

\author{
JONATHAN B. WIENER *
}

Greenhouse gases trap heat in the Earth's atmosphere, warming the Earth's surface in a process that scientists call "radiative forcing." Some radiative forcing is essential: without it, energy received from the Sun's rays would escape back into space, the Earth's surface would be colder than the freezing point of water, and life would not survive. But with too much (or too rapid) radiative forcing, the climate changes in ways that harm ecosystems and human societies. As the amount of greenhouse gases (GHGs) in the atmosphere has grown, so has concern that their enhanced radiative forcing effect may induce dangerous climate change. Policy makers have therefore sought ways to forestall climate change and to cope with its impacts. ${ }^{2}$

Perkins Professor of Law, and Professor of Environmental Policy and of Public Policy Studies, Duke University; University Fellow, Resources for the Future (RFF). This paper was prepared as a contribution to the symposium on "Breaking the Logjam: An Environmental Law for the 21 st Century," held at NYU Law School, 28-29 March 2008. The author is grateful for helpful comments from Robert Crandall, Donald Elliott, Nathaniel Keohane, William Pederson, Jedediah Purdy, David Schoenbrod, Richard Stewart, and Katrina Wyman; and for research assistance from Natasha Pajic.

1 See COMM. ON RADIATIVE Forcing EFfECts on Climate, NaT'L Research Council, Radiative Forcing of Climate CHange: ExPANDing THE CONCEPT AND ADDRESSING UNCERTAINTIES (2005); WORKING GROUP I, INTERgovernmeNTAL PANEL ON Climate CHANGE, IPCC WORKING GROUP I CONTRIBUtion to the Fourth ASSESSMENT RePORT, Climate Change 2007: THE Physical SCIENCE BASIS, SuMmary FOR POLICY Makers 2-5 (2007), available at http://ipcc-wgl.ucar.edu/wg1/docs/WG1AR4_SPM_ PlenaryApproved.pdf.

2 The organizers of the Breaking the Logjam symposium-Dick Stewart, David Schoenbrod, and Katrina Wyman-specifically asked the symposium authors to address the design of environmental law, and not the degree of protection warranted nor the seriousness of the problem being addressed. Thus, this article does not discuss how serious a threat climate change is nor how stringent limits on greenhouse gas emissions (or other policy measures) should be. For discussion of those questions, see infra notes 65-67 and accompanying text (on benefit-cost studies of optimal climate change policy); RICHARD B. 
In turn, a serious policy to combat climate change can-and should-radiate a powerful influence, driving important improvements in environmental law. This article argues that welldesigned climate policy will both address the climate problem, and help "break the logjam" by propelling significant reforms in the structure of U.S. environmental governance.

The "logjam" metaphor refers to the absence of major new environmental legislation enacted by the U.S. Congress since the1990s. ${ }^{3}$ To the extent that the "logjam" is a real problem, the root causes are not only generalized partisan gridlock (afflicting all types of policy), but also the particular features of environmental law that have diminished its appeal and blocked its advance. The design of much past environmental law has suffered from four key problems: fragmentation, insensitivity to tradeoffs, rigid

Stewart \& Jonathan B. Wiener, Reconstructing Climate Policy: Beyond Kyoto (2003) [hereinafter ReCOnSTRuCting Climate POLICY] (arguing that despite uncertainties, climate change is a serious risk worth combating through well-designed cost-effective policies).

3 For description and evidence of the "logjam," see Carol A. Casazza Herman, David Schoenbrod, Richard B. Stewart \& Katrina Wyman, Breaking the Logjam: Environmental Reform for the New Congress and Administration, 17 N.Y.U. ENVTL. L.J. 1 (2008); Richard LAzARUS, The MAKing of ENVIRONMENTAL LAW 125-65. (2004) (documenting the slowdown in enactment of major new environmental legislation by the U.S. Congress since about 1990 , and the widening divergence of environmental attitudes between the two main political parties since that time).

At the same time, however, the period from 1990 to 2007 has not been silent: there have been major U.S. environmental policy actions undertaken during that time, including, among others, the enormous task of implementing the numerous programs launched in the 1990 CAA Amendments, including large new regulatory programs on acid rain, hazardous air pollutants (air toxics), and substances that deplete stratospheric ozone; the enactment in 1996 of the major Safe Drinking Water Act amendments and the Food Quality Protection Act, both with strong bipartisan backing; the adoption in 1997 and again in 2008 of major EPA rules on ground-level ozone and fine particulate matter; the adoption of stringent new rules on diesel engine emissions by both the Clinton and subsequent Bush administrations; an array of land use policies including large new protected areas of federal lands; the Clean Air Interstate Rule adopted in 2004 (now in litigation with the possibility of legislative enactment); and the international agreement to phase out HCFCs (potent agents of stratospheric ozone depletion, and also potent greenhouse gases) in 2007. For discussion of these and other developments, see Jonathan B. Wiener, Convergence, Divergence, and Complexity in U.S. and European Risk Regulation, in GREEN GIANTS?: ENVIRONMENTAL POLICIES OF THE UNITED STATES AND THE EUROPEAN UNION 73-109 (Norman Vig \& Michael Faure eds., 2004). 
prescriptive commands, and mismatched scale. ${ }^{4}$ These are problems with the design of regulatory systems, not a rejection of the overall objective of environmental law to protect ecosystems and human health. These four design defects raised the costs, reduced the benefits, and increased the countervailing risks of many of the environmental laws enacted in the $1960 \mathrm{~s}, 70 \mathrm{~s}$, and $80 \mathrm{~s} .5$ The "logjam" since the 1990 s reflects the accretion of these problems in the accumulated edifice of environmental law built up since the 1960s, with predictable political results: the growing perception (perhaps overstated, but perceived nonetheless) that environmental law is costly and rigid yet generates limited gains. Industry and political conservatives (and many centrists) opposed the high costs. Attempting to force the Congress and the public to adopt new laws perceived as very costly became a losing battle. Meanwhile, many environmental advocacy groups (though not all) resisted design strategies to reduce the cost of environmental law, notably market-based economic incentive systems such as emissions trading, in part because these groups feared that such flexible incentives would spawn damaging and unfair hotspots of concentrated pollution-in effect, a risk-risk tradeoff. The principal environmental laws successfully enacted since the 1990s-breakouts from the logjam-were laws consciously designed to reduce costs and overcome the prior design defects: for example, the 1990 Clean Air Act (CAA) Amendments used an ambitious emissions trading program to reduce acid rain (despite some concerns about hotspots), and the 1996 Safe Drinking Water Act amendments authorized attention to both risk-risk and costbenefit tradeoffs.

A basic lesson from this history is that environmental protection, like other social goods, will generally be adopted more frequently and more ambitiously if its design promises to be less costly and more effective. Higher-cost and lower-payoff policy designs are less likely to be adopted. Environmental advocates frustrated by the logjam in environmental law should see improved

4 See Stewart, Schoenbrod \& Wyman, supra note 3.

5 See Stephen G. Breyer, Breaking the Vicious Circle: Toward EFFECTIVE RISK REgUlation (1993); RISK VS. RISK: TRADEOFFS IN PROTECTING HEALTH AND THE ENVIRONMENT (John D. Graham \& Jonathan B. Wiener eds., 1995); J. Clarence Davies \& Jan Mazurek, Pollution Control in the UNTTED STATES (1998). 
(more cost-effective) regulatory design as a key element of the way forward.

If the logjam persists into the future, then the adoption of serious climate change legislation would be a formidable jambreaking step-perhaps the greatest jam-breaker ever. The logjam looks ripe for breaking in 2009 , because it will be the first year of the new Presidential administration (both President-elect Barack Obama and Senator John McCain have endorsed strong climate legislation); and because 2009 will also be the year in which the Bali Action Plan (adopted in December 2007) calls for agreement to be reached in Copenhagen on a new climate change treaty to follow and improve on the Kyoto Protocol. ${ }^{6}$ Sir Nick Stern's recent report calls climate change "the greatest and widest-ranging market failure ever seen"7 - which would make a successful legal regime to combat climate change the greatest environmental law ever seen. And by the same criterion, the absence of good climate policy—or botching it-would be the greatest government failure ever seen.

To meet this challenge, good climate policy will learn from experience and improve on the design of past environmental law, fostering four counterpart solutions to the prior design defects: cross-cutting integration instead of fragmentation, attention to tradeoffs instead of their neglect, flexible incentive-based policy instruments such as emissions trading in place of rigid prescriptive commands, and optimal instead of mismatched scale. This article advocates a design for U.S. climate policy that embodies these four design solutions. There are numerous policy options for addressing climate change; this article focuses on policies to limit GHG emissions. It proposes a policy that is comprehensive in its coverage of multiple pollutants (all GHGs), their sources and sinks, multiple sectors (indeed economy-wide), and multiple issues currently divided among separate agencies. It advocates explicit

6 Conference of the Parties, United Nations Framework Convention on Climate Change, Dec. 3-15, 2007, Decision 1/CP.13: Bali Action Plan ף 1, U.N. Doc. FCCC/CP/2007/6/Add.1 (Mar. 14, 2008) [hereinafter Bali Action Plan] available at http://unfccc.int/resource/docs/2007/cop13/eng/06a01.pdf\#page=3.

7 Nicholas Stern, The Stern Review: The Economics of Climate Change, Executive Summary i (2006), available at http://www.hmtreasury.gov.uk/media/4/3/executive_summary.pdf. One can agree with this characterization even if one does not agree with the specific numerical figures in the Stern Review's estimate of climate change damages or policy costs. 
attention to tradeoffs, both benefit-cost and risk-risk (including both ancillary harms and ancillary benefits), in setting the goals and boundaries of climate policy. It advocates the use of flexible market-based incentives through an efficient cap-and-trade system, with gradual multi-year emissions reduction schedules that are reviewed periodically in light of new information. And it advocates matching the legal regime to the environmental and economic scale of the climate problem, starting at the global level, engaging all the major emitting countries (including the U.S. and China), and then implementing at the national and sub-national levels-rather than a patchwork bottom-up approach. ${ }^{8}$ The article addresses how this proposal would help overcome political obstacles. It focuses on the structure of environmental

8 In a series of publications over the past two decades, I examined in greater detail the pros and cons of this comprehensive global GHG cap-and-trade system, compared to a $\mathrm{CO}_{2}$-only policy, an emissions tax, and a prescriptive technology standard to limit emissions. See, e.g., RECONSTRUCTING CLIMATE PoliCY, supra note 2; Jonathan B. Wiener, Designing Global Climate Regulation, in Climate Change Policy 151-87 (Stephen Schneider, Armin Rosencranz \& John-O Niles eds., 2002); Richard B. Stewart \& Jonathan B. Wiener, The Comprehensive Approach to Global Climate Policy, 9 ARIz. J. INT'L \& CoMP. L. 83 (1992); Jonathan B. Wiener, Global Environmental Regulation: Instrument Choice in Legal Context, 108 YALE L.J. 677 (1999).

For a recent and carefully articulated proposal of a similar cap-and-trade system for the United States, see Robert N. Stavins, A Meaningful U.S. Cap-andTrade System to Address Climate Change, 32 HARV. ENVTL. L. REV. 293 (2008). Other policy options could include: federal subsidies or tax credits for technology adoption, federally funded $R \& D$ on new technologies, policies to protect and enhance carbon sinks such as forests, information disclosure requirements such as a national GHG emissions inventory, and geoengineering projects (such as using particles or mirrors to deflect some solar radiation away from the earth). Some of these policies could complement a GHG emissions limitation policy. For example, a federal technology R\&D program could be adopted to overcome the market failure in basic research and intellectual property incentives and to spur innovation of new technologies. At the same time a GHG emissions limit could be adopted through a cap-and-trade or tax system to overcome the market failure in environmental externalities, which would have the ancillary benefit of encouraging the diffusion and adoption of those new technologies. See Adam B. Jaffe, Richard G. Newell \& Robert N. Stavins, A Tale of Two Market Failures: Technology and Environmental Policy, 54 ECOLOGICAL ECON. 164 (2005). Further, adaptation policies could be adopted to help cope with the impacts of climate change, such as sea level rise, storm damage, droughts or floods or other changes in water cycles, agricultural dislocations, the spread of tropical diseases, heat- and cold-related illnesses, species extinctions and other ecosystem disturbances, ocean acidification, and other effects. 
governance, not on the degree of protection. And it explores how such a climate policy would influence other areas of law.

Among environmental issues, climate change is ideally suited to these improved policy design features because its potentially high cost demands a low-cost policy instrument, because GHGs do not generally pose local impacts that threaten hotspots, and because the global scale and economy-wide character of GHG emissions are well understood.

The harms from unchecked climate change (even accounting for uncertainties), and the costs of climate policy, are both substantially larger than those of most or all other environmental issues. Countries see their standard of living and their geopolitical future tied to the activities that emit GHGs. Climate policy is thus not only environmental policy, it is economic policy, and it is power politics. The costs of major GHG reductions are so high that no one seriously advocates enacting a law for GHGs that ignores cost, or that requires the U.S. Environmental Protection Agency (EPA) to set pollution levels without considering cost (as the courts have held that part of the CAA requires for conventional pollutants). Industry generally wants costs considered and limited (although occasionally some industry subgroups seek expensive regulations to raise their rivals' costs), and it is becoming (or should be) understood by environmentalists as well that the higher the cost of a climate policy, the less ambitious the policy that legislators will be willing to enact. The fact that GHGs mix globally in the atmosphere means that hotspots are not a major concern-indeed much less of a concern than they were in the successful 1990 acid rain trading program-and thus environmental advocates can espouse the flexibility of a cap-andtrade system for GHGs. This combination of features substantially explains the growing consensus in the United States in favor of an incentive-based cap-and-trade system to limit GHG emissions. ${ }^{9}$ Meanwhile, the sources and sinks of GHGs are ubiquitousmultiple gases in every sector and in every major country-and the

9 See J.R. DeShazo \& Jody Freeman, Timing and Form of Federal Regulation: The Case of Climate Change, 155 U. PA. L. REV. 1499, 1550-58 (2007) (explaining how these factors, along with the use of allowance allocations to placate those who bear costs and reward early emissions reductions, together account for the observed support for a GHG cap-and-trade system by both industry and environmental groups, and at both the state and federal level). 
mobility of economic activities in a globalizing world is so great that broad scale and cross-cutting integration are crucial to the success of climate policy. Small scale or narrowly targeted policies will just induce "leakage" of emitting activities, undermining the policy's environmental effectiveness and discouraging legislators from enacting it.

Climate change policy is too important to neglect, too important to get wrong, and too consequential to address without integrating across the economy, confronting tradeoffs in costs and risks, using the most cost-effective incentive instruments, and matching the relevant scale. Where some past environmental policy has been enacted without addressing these four issues, climate policy is just too big to do so. ${ }^{10}$

Two decades ago, policy discussions were far from this approach. Instead, policy discussions in 1989-90 focused on a narrow and rigid approach that would have regulated carbon dioxide alone (not other GHGs), from sources (neglecting sinks) in the energy sector only (omitting other sectors) using rigid regulatory instruments, in wealthy countries only. I and others criticized this approach and proposed a comprehensive, incentivebased policy design. ${ }^{11}$ The international climate treaties (the Framework Convention on Climate Change (FCCC) in 1992, and the Kyoto Protocol in 1997) made partial headway, adopting a comprehensive approach and authorizing a cap-and-trade incentive system, but omitted effective action by China and other major developing country emitters, ultimately losing U.S. participation as a result. ${ }^{12}$ The leading bills in the current U.S. Congress would adopt an economy-wide multi-gas cap-and-trade system, but still omit some sectors, and leave open how China and other emerging great powers would be engaged. ${ }^{13}$ The political machinery. is

10 For commentary on the seriousness of climate change and how stringent climate policy should be, see supra note 2 .

11 I detailed this history in Jonathan B. Wiener, Something Borrowed for Something Blue: Legal Transplants and the Evolution of Global Environmental Law, 27 ECOLOGY L. Q. 1295, 1309 (2001). We made our proposals within the U.S. government and then to the international negotiating committee. See id. We published papers advocating our approach in 1990-92, including Stewart \& Wiener, The Comprehensive Approach to Global Climate Policy, supra note 8.

12 See Reconstructing Climate Policy, supra note 2, at 1-17.

13 See, e.g., America's Climate Security Act, S.2191, 110th Cong. (2007). A caveat is that ACSA, also known as the Lieberman-Warner bill, initially covers 
gradually groping toward a climate policy that matches the scope of the problem-system it is meant to regulate. ${ }^{14}$ If climate policy is to break the logjam, this article suggests how it should be designed to do so.

\section{INTEGRATION}

Traditionally, U.S. environmental law has advanced piecemeal, adopting statutes targeted at specific media (such as air, water, or land) or problems (such as oil spills, solid waste, species loss), often in response to particular incidents, and delegating implementation to distinct agencies or sub-agency programs overseen by counterpart legislative subcommittees. The result has been a fragmented pattern of authority, with environmental issues compartmentalized and regulated by decision makers who focus narrowly on each bounded domain. ${ }^{\text {IS }}$

The EPA, created in 1970, was initially intended to be an integrated actor taking a comprehensive, holistic view of the environment, but it quickly became subdivided into separate programs for air, surface water, drinking water, wastes, and pesticides. $^{16}$ And other agencies took on environmental management responsibilities as well, including the Department of Agriculture's (USDA) Forest Service, the Department of Interior's Bureau of Land Management (BLM) and Fish \& Wildlife Service (FWS), the Department of Energy (DOE), the Department of Commerce's National Oceanic \& Atmospheric Administration (NOAA) and National Marine Fisheries Service (NMFS), the Department of Labor's Occupational Safety \& Health Administration (OSHA), the Department of Defense's Army Corps

electric power, industry and transportation, but not agriculture and forestry.

14 See StePHEN G. BREYer, REgUlation AND ITS REFORM (1982) (criticizing "mismatches" between regulatory policy designs and the problems to be regulated); James M. Buchanan \& GoRdon Tullock, THE Calculus OF CONSENT 113 (1962) (proposing that optimal jurisdiction size match the scope of the externality to be regulated, subject to the costs of decision making).

15 See INTEgRated Pollution CONTROL (Nigel Haigh \& Frances Irwin eds., 1990); Lakshman Guruswamy, Comment, The Case for Integrated Pollution Control, 54 LAW. \& CONTEMP. PROBS. 41, 42 (1991); Jonathan B. Wiener \& John D. Graham, Resolving Risk Tradeoffs in RISK vS. RISK, supra note 5, at $228-42$.

16 See Alfred A. Marcus, EPA's Organizational Structure, 54 LAW. \& CONTEMP. PROBS. 5 (1991). 
of Engineers, the Department of Transportation's National Highway Traffic Safety Administration (DOT/NHTSA), and the Coast Guard (once in Transportation, now in the Department of Homeland Security), as well as others. At the White House, the Council on Environmental Quality (CEQ) and the Office of Management and Budget (OMB) attempt to coordinate these and other agencies, but are only partially successful given the separate statutes, funding, officers, and constituencies of each bureaucratic domain.

Fragmentation can yield conflicting policies that frustrate each other, or duplicative policies that waste effort. In the climate arena, one example is the contested jurisdiction over automobile emissions of carbon dioxide $\left(\mathrm{CO}_{2}\right)$ (regulated by EPA) and automobile fuel economy (regulated by DOT/NHTSA), because with current combustion technology, efforts to reduce $\mathrm{CO}_{2}$ emissions seem to imply improvements in fuel economy.

The fragmented structure also leaves some gaps unaddressed. ${ }^{17}$ Notable among these is the weak or absent federal regulatory authority over non-point source water pollution (run-off from farms and impermeable surfaces) ${ }^{18}$ and, as this article discusses, climate change.

And the fact that environmental systems are interconnected means that narrowly targeted decisions by fragmented agencies can also impose undesirable spillover effects on other domainsone form of "risk-risk tradeoffs." 19 For example, rules to reduce one kind of pollution (such as air pollution) may yield cross-media shifts that increase pollution into other media (such as water pollution or solid waste). ${ }^{20}$ EPA rules to reduce outdoor air

17 See William W. Buzbee, Recognizing the Regulatory Commons: A Theory of Regulatory Gaps, 89 IOWA L. REV. 1 (2003).

${ }_{18}$ See J.B. Ruhl, Farms, Their Environmental Harms, and Environmental Law, 27 ECOLOGY L. Q. 263, 287-91 (2000) (describing scope and deleterious effects of agricultural run-off, a "leading source of impairment in the Nation's rivers").

19 See generally RISK VS. RISK, supra note 5 (advancing and analyzing the concept of risk-risk tradeoffs).

20 See Joel A. TARR, THE SEARCH For THE Ultimate Sink (1996) (discussing shifts of pollution from one environmental medium or "sink" to another as a result of narrowly targeted regulations aimed at one medium at a time). 
pollution may increase indoor air pollution regulated by OSHA. ${ }^{21}$ EPA or OSHA rules to phase out asbestos (including in automobile brake linings) may increase traffic fatalities regulated by NHTSA. ${ }^{22}$

One solution to the current fragmentation would be structural integration through the merger of closely related agencies. ${ }^{23}$ This could offer improved decisionmaking by avoiding conflicts and duplications, filling gaps, and internalizing what had been crossdomain risk-risk tradeoffs within the same agency. But risk-risk tradeoffs can also occur within one agency's domain, as when EPA's air pollution rules induce greater water pollution or solid waste, or when NHTSA's fuel economy rules affect traffic safety. And the transaction costs of such mergers should not be overlooked; consider the recent strenuous efforts to combine numerous agencies into the new Department of Homeland Security. Centralizing power in one super-agency can slow down decisions, encourage excessive reliance on a single point of view, and magnify errors. More important than structural merger, then, is an integrated decision framework in which each agency takes into account side effects on other domains (and within its own); and a supervisory body that can identify and fill gaps, reconcile tradeoffs, and coordinate multi-agency actions.

Dealing with climate change highlights the shortcomings of this fragmented structure. Because GHGs are emitted from virtually every sector of human activity, including electricity generation, industry, buildings, transportation, agriculture, and

${ }^{21}$ See Adam M. Finkel \& P. Barry Ryan, Risk in the Workplace: Where Analysis Began and Problems Remain Unsolved, in RISK ASSESSMENT FOR ENVIRONMENTAL Health 204 (Mark Robson \& William Toscano, eds., 2007) (describing this risk tradeoff and an OSHA-EPA agreement in 1999 to address it); OSHA and EPA Announce Coordinated Enforcement Effort, Jan. 23, 2000, available at http://isu1.indstate.edu/terc/transource/news/news_ID $=2 . h t m$ ? news_ID $=2$.

22 See Corrosion Proof Fittings v. U.S. EPA, 947 F.2d 1201, 1225 (5th Cir. 1991).

${ }^{23}$ See Wiener \& Graham, supra note 15 , at 252-60. The UK attempted such a merger in the 1990s. See Neil Carter \& Philip Lowe, The Establishment of a Cross-Sector Environment Agency, in UK ENVIRONMENTAL POLICY IN THE 1990s 38 (T. Gray ed., 1995). China recently announced such mergers across its government, including the creation of a new larger environment "superministry." See Jim Yardley, China Retools its Government in Efficiency Push, N.Y. TIMES, Mar. 12, 2008, available at http://www.nytimes.com/2008/03/12/world/ asia/12china.html. 
forestry, it makes little sense to target regulation one sector at a time. Narrowly targeted rules would be both less environmentally effective and more costly than economy-wide approaches. Regulating one sector at a time may induce "leakage" of emitting activities from that sector to others, undermining the environmental efficacy of the regulation. ${ }^{24}$ And narrow sectorspecific regulation would inhibit the flexibility to find the least costly emissions abatement opportunities across all sectors.

But no one agency or statutory regime currently has authority over all, or even many, of these sectors affecting the climate. In the absence of new federal legislation governing GHG emissions from the economy as a whole, we have recently witnessed a scattershot of legal efforts across the array of statutes and agencies: litigation to force EPA to regulate $\mathrm{CO}_{2}$ emissions under the CAA (and potential EPA regulation under the CAA yet to come), ${ }^{25}$ the creation of a new energy technology agency (ARPA-E) but so far no funding for its activities; ${ }^{26}$ a new energy law with provisions to increase vehicle fuel economy; ${ }^{27}$ a decision by the Fish \& Wildlife Service (FWS) to list polar bears as a threatened species (due to Arctic ice melting) under the Endangered Species Act; ${ }^{28}$ litigation to force diverse federal agencies to evaluate the climate impacts of

${ }^{24}$ Leakage across countries is discussed further below. Leakage across economic sectors might occur, for example, when a law that regulates GHG emissions from fossil fuel combustion in the energy sector (but that does not regulate the agriculture or forest sectors) induces increased use of biofuels grown on farms with associated increased emissions of GHGs from the farms (and decreased GHG sinks due to conversion of forest land to farm land). See Timothy Searchinger, et al., Use of U.S. Croplands for Biofuels Increases Greenhouse Gases Through Emissions from Land Use Change, 319 SCIENCE 1238 (2008), available at http://www.sciencemag.org/cgi/content/ abstract/1151861v1. Preventing such cross-sector leakage requires integration of the significant emitting sectors into a comprehensive approach. For a discussion of the inclusion of agriculture and forests in a comprehensive climate policy, see ReCONSTRUCting Climate Policy, supra note 2; John M. Reilly \& Malcolm O. Asadoorian, Mitigation of Greenhouse Gas Emissions from Land Use: Creating Incentives within Greenhouse Gas EmissionsTrading Systems, 80 CLIMATIC CHANGE 173 (2007); HARNESSING FARMS AND FORESTS IN THE LOW-CARBON ECONOMY: How to Create, MEASURE, AND VERIFY GREenhouse Gas OFFSETS (Zach Willey \& Bill Chameides eds., 2007).

${ }_{25}$ See, e.g., Massachusetts v. EPA, 127 S. Ct. 1438 (2007).

26 Advanced Research Projects Agency-Energy, 42 U.S.C. $\S 16538$ (2000).

27 Energy Independence and Security Act, Pub. Law No. 110-140 § 102, 121

Stat. 1492 (Dec. 19, 2007), section 102 (amending 42 U.S.C. $\S 32902$ ).

28 See 73 Fed. Reg. 28,306 (May 15, 2008). 
their projects under the National Environmental Policy Act (NEPA), the Administrative Procedure Act, and the decision criteria of the relevant regulatory statute, ${ }^{29}$ litigation in international fora seeking recognition of human rights claims when local cultures are injured by global warming; ${ }^{30}$ the adoption by several U.S. state governments of GHG control laws (such as in California and the Western Climate Initiative, the northeastern states joining the Regional Greenhouse Gas Initiative (RGGI), and others); ${ }^{31}$ numerous cities' adoption of GHG control efforts (in part through an agreement among hundreds of mayors), ${ }^{32}$ common law nuisance suits against GHG emitters (so far unsuccessful), ${ }^{33}$ shareholders' efforts to force corporate boards to disclose their firms' climate-related risks (or to persuade the Securities and Exchange Commission (SEC) to mandate such disclosure) $;^{34}$ and others. These diverse initiatives are creative, but they are also uncoordinated and incomplete, and have only a faint hope of coalescing into a coherent national regulatory strategy. They are understandable expressions of frustration with the lack of a national policy.

One might think that coherent national regulation of GHG

29 See, e.g., Center for Biological Diversity v. NHTSA, 508 F.3d 508 (9th Cir. 2007), and the Sierra Club, Natural Resource Defense Council, and International Center for Technology Assessment's 2008 petition to CEQ to require climate analyses in all environmental impact statements (EIS), available at http://www.icta.org/doc/CEQ\%20Petition\%20Final\%20Version\%202-2808.pdf.

30 Such as the claim brought by the Inuit Circumpolar Conference in the Inter-American Commission on Human Rights in 2005, which argued that global warming caused by United States is destroying the cultures and livelihoods of indigenous peoples. CENTER FOR INTERNATIONAL ENVIRONMENTAL LAW, INUIT File PETITION With INTER-AMERICAN COMMISSION ON HuMaN RIGHTS FoR DANGEROUS IMPACTS OF CLIMATE CHANGE (2005), available at http://www.ciel.org/Publications/COP10_Handout_EJCIEL.pdf.

31 See DeShazo \& Freeman, supra note 9, at 1521-30 (surveying the states' climate policies).

32 See U.S. Conference of Mayors, Climate Protection Agreement (2005), available at http://www.usmayors.org/climateprotection/agreement.htm. The agreement lists more than 800 mayors as signatories as of Sept. 16, 2008. Id.

33 See Connecticut v. Am. Elec. Power Co., 406 F. Supp. 2 d 265 (S.D.N.Y. 2005); California v. Gen. Motors Corp., WL 2726871 (N. D. Cal. 2007).

${ }^{34}$ See Investors ACHIEve Major Company Commitments on Climate CHANGE, CERES.ORG (2008), available at https:/www.ceres.org/ NETCOMMUNITY/SSLPage .aspx?pid=928\&srcid=705. 
emissions could be organized through the existing air pollution laws, primarily the federal CAA. But for several years EPA denied that it had the authority to regulate GHGs under the CAA (until April 2007, when the U.S. Supreme Court held that it did have such authority, in Massachusetts v. EPA). And in any event the current federal CAA may not offer EPA effective instruments for GHG emissions control. After Massachusetts $v$. EPA, the agency has the power to regulate emissions of GHGs from new motor vehicles and fuels, and EPA says it is now preparing to propose such rules (while denying California the authority to adopt its own alternative rule). ${ }^{35}$ But even if EPA promulgates a regulation soon, it will have limited effect because new vehicles penetrate the full fleet only slowly, and by increasing the cost of new vehicles, such rules encourage people to keep their old (dirtier) cars longer. There may be no available on-board filter to remove GHGs from the tailpipe, nor an alternative fuel (short of a costly experimental new engine type such as a hydrogen fuel cell) that markedly reduces GHG emissions (corn ethanol emits no less than gasoline, and possibly much more if $\mathrm{CO}_{2}$-sequestering forests are cleared to grow more crops; ${ }^{36}$ cellulosic ethanol may do better, and gas-electric hybrids may help, but benefits from plug-in electric vehicles depend on the power source from which they get their electric charge). EPA has little authority over existing vehicles (except through regulating fuels), nor over how many miles the vehicles are driven, public mass transit systems, or land use planning.

35 After the court decision in Massachusetts v. EPA in April 2007, President Bush issued an Executive Order directing EPA, DOT, DOE, and USDA to coordinate a regulatory response regarding $\mathrm{CO}_{2}$ emissions from vehicles. Exec. Order No. 13,432, 72 Fed. Reg. 27717 (May 14, 2007). Meanwhile, California was seeking a waiver from EPA under the federal CAA to enable California to adopt its own rules for GHG emissions from vehicles (as it has sought for other vehicle air pollutants in the past). EPA Administrator Stephen Johnson denied the California request for a waiver in December 2007, with an explanation published at $73^{\circ}$ Fed. Reg. 12,156 (Mar. 6, 2008), arguing in part that GHG emissions require a national policy. EPA's own national rule on GHGs from vehicles has not yet been promulgated. EPA has issued an Advanced Notice of Proposed Rulemaking. See Regulating Greenhouse Gas Emissions Under the Clean Air Act, 73 Fed. Reg. 44,353 (July 30, 2008) (discussing options and problems with GHG regulation under the CAA), available at http://www.epa.gov/climatechange/anpr.html.

${ }^{36}$ See Searchinger, supra note 24. 
After Massachusetts v. EPA, similar language in other parts of the CAA probably also authorizes EPA to regulate emissions of GHGs from stationary sources such as electric power plants and industrial facilities. But these CAA provisions are a poor fit for GHGs. EPA can require emissions controls at new or modified stationary sources, but these rules penetrate the full economy only slowly, plus they encourage firms to operate their old (dirtier) facilities longer. For existing sources, EPA must mainly rely on a statutory two-step in which EPA sets a national ambient air quality standard (NAAQS) limiting the total amount of the pollutant in the air, and then the states control the emissions (via state implementation plans or SIPs) to attain that ambient standard within each state. Yet this approach is virtually impossible for a globally mixing pollutant like $\mathrm{CO}_{2}$, whose ambient level within each state depends on global, not local, emissions. (This point is discussed further below in the section on Scale.) Thus, a new integrated approach is warranted.

\section{TRADEOFFS}

Current laws and agency decisions often do not take adequate account of tradeoffs. At least two kinds of tradeoffs are important: risk-risk tradeoffs, and benefit-cost tradeoffs. Both should be considered in making policy to prevent climate change. Indeed, the U.S. has already committed to doing so. The 1992 Framework Convention on Climate Change, to which the U.S. is a party, provides in Article 4(1)(f) that each party shall: "employ appropriate methods, for example impact assessments, formulated and determined nationally, with a view to minimizing adverse effects on the economy, on public health and on the quality of the environment, of projects or measures undertaken by them to mitigate or adapt to climate change."

\section{A. Risk-Risk}

Risk-risk tradeoffs occur when an intervention to reduce a target risk also induces a change in another, ancillary risk. This change can be an increase in the ancillary risk (called an ancillary harm, side-effect, countervailing risk or dis-benefit), or a decrease in the ancillary risk (called an ancillary benefit, coincident risk, or 
co-benefit). ${ }^{37}$ In much personal and government decision making, only the change in the target risk is considered. In the real world of interconnected economic and ecological systems, each intervention affects a portfolio of multiple risks. Sound decision making should evaluate these effects in concert and seek to reduce overall risk. ${ }^{38}$

As noted above, fragmentation of authority can lead to riskrisk tradeoffs. But even with cross-agency integration, narrowly drawn climate change policies could pose risk-risk tradeoffs. For example:

$>$ Reductions in coal and oil combustion may involve risks from the substitute energy sources, such as natural gas (e.g. national security risks from dependence on foreign supplies; explosions at liquified natural gas facilities), nuclear fission (e.g. radioactive waste; accidents; weapons proliferation), solar power (e.g. biodiversity loss from land devoted to solar panel arrays), hydrogen fuels, or nuclear fusion.

$>$ Cross-gas shifts: under a climate policy regulating only $\mathrm{CO} 2$, well-intentioned reductions in $\mathrm{CO}_{2}$ emissions could yield increases in emissions of other (unregulated) $\mathrm{GHGs},{ }^{39}$

37 See RiSK vS. RISK, supra note 5, at 1-41. Attention to ancillary benefits on equal footing with ancillary harms is urged in Samuel J. Rascoff and Richard L. Revesz, The Biases of Risk Tradeoff Analysis: Towards Parity in Health and Environmental Regulatory Policy, 69 U. CHI. L. REV. 1763 (2002). I agree; the goal should be an evenhanded evaluation of the full portfolio of important consequences induced by each intervention. See, e.g., RISK VS. RISK, supra note 5, at 2; Jessica Stern \& Jonathan B. Wiener, Precaution Against Terrorism, in MANAGING STRATEGIC SURPRISE: LESSONS FROM RISK MANAGEMENT AND RISK ASSESSMENT 110-83 (Paul Bracken, Ian Bremmer \& David Gordon eds., 2008); Jonathan B. Wiener, Managing the Iatrogenic Risks of Risk Management, 9 RISK: HEALTH SAFETY \& ENVIRONMENT 39 (1998).

${ }^{38}$ Risk-risk tradeoffs can be incorporated into benefit-cost analysis, but they are conceptually distinct. Risk-risk tradeoffs are the vector of positive and negative effects on the benefits side, irrespective of compliance cost. And in practice, benefit-cost analysis often ignores risk-risk tradeoffs by focusing only on the target risk and on industry compliance cost. President Clinton's Executive Order 12,866 (1993) and subsequent OMB guidance (especially Circular A-4 (2003)) have instructed agencies to consider risk-risk tradeoffs, but OMB's standard scoresheet (attached to Circular A-4) still omits ancillary risks. See Exec. Order No. 12866, 58 Fed. Reg. 51,735 (Sept. 30, 1993); OfFICE OF Mgmt. \& Budget, Executive Office of the President, Circular No. A-4, REGULATORY ANALYSIS 3, 26, 47 (2003).

39 See Stewart \& Wiener, The Comprehensive Approach to Global Climate Policy, supra note 8, at 91; Wiener, Protecting the Global Environment, in RISK 
such as increased methane $\left(\mathrm{CH}_{4}\right)$ emissions from leaky natural gas systems in some countries, or increased nitrous oxide $\left(\mathrm{N}_{2} \mathrm{O}\right)$ emissions from fertilizing corn to make ethanol (or increased $\mathrm{CO}_{2}$ levels from converting forests to cropland for biofuels, noted above), or increased perfluorocarbon (PFC) emissions from manufacturing aluminum to use in vehicles instead of heavier (less fuel-efficient) steel. Using the Intergovernmental Panel on Climate Change's (IPCC) index of global warming potential, $\mathrm{CH}_{4}, \mathrm{~N}_{2} \mathrm{O}$ and PFCs are, respectively, about 25 times, 300 times, and 7,000 to 12,000 times more potent global warming gases than is $\mathrm{CO}_{2}$ (per kilogram over 100 years). ${ }^{40}$ Hence even small increases in emissions of these other gases could erase or override the warming-preventive benefits of reducing $\mathrm{CO}_{2}$ emissions.

$>$ Similarly, phasing out CFCs (to protect the stratospheric ozone layer) led to the use of substitute chemicals such as hydrochlorofluorocarbons (HCFCs) and hydrofluorocarbons (HFCs). Because HCFCs also deplete stratospheric ozone, the HCFCs are now being phased out as well under the same treaties (the Montreal Protocol and its follow-on accords) that phased out CFCs. But because the HFCs do not contain chlorine and thus do not deplete stratospheric

VS. RISK, supra note 5, at 209; RECONSTRUCTING CLIMATE POLICY, supra note 2, at 60-63. Robert Stavins has proposed a cap-and-trade system limited to $\mathrm{CO}_{2}$ only. See Stavins, supra note 8 . While his proposal would make offset credits available for reductions in other GHGs, it does not address the countervailing risk of cross-gas shifts to emissions of unregulated non- $\mathrm{CO}_{2}$ gases. See id. at 323.

40 See Forster, P., et al, Changes in Atmospheric Constituents and in Radiative Forcing, ch. 2, in IPCC WORKING GROUP I CONTRIBUTION TO THE Fourth Assessment RePort, Climate Change 2007: The Physical SCIENCE BASIS, supra note 1, at 212 tbl.2.14 (showing the Global Warming potential (GWP) index). Studies continue to assess the potency of GHGs not yet regulated under the Kyoto Protocol, such as nitrogen trifluoride. See Michael J. Prather \& Juno Hsu, $\mathrm{NF}_{3}$ : The Greenhouse Gas Missing from Kyoto, 35 Geophys. Res. Letters L12810 (2008), available at http://www.agu.org/pubs/ crossref/2008/2008GL034542.shtml. Meanwhile, compared to the IPCC GWP index, more accurate metrics of the relative climate impacts of different gases can be obtained through global climate models that account for the changing atmosphere, see Alan S. Manne \& Richard G. Richels, An alternative approach to establishing trade-offs among greenhouse gases, 410 NATURE 675 (2001), and through indices that account for the valuation of environmental impacts. See James K. Hammitt, et al., A welfare-based index for assessing environmental effects of greenhouse-gas emissions, 381 NATURE 301 (1996). 
ozone, they are not being addressed under those treaties; yet they are potent GHGs (140 to 11,700 times more potent than $\mathrm{CO}_{2}$ ). Thus, in substituting HFCs for CFCs, ozone depletion risk has been reduced while global climate risk has been increased. ${ }^{41}$

$>$ Under some circumstances, sequestration of $\mathrm{CO}_{2}$ in forests could be increased by clearing a mature existing forest and replanting the land with a young fast-growing type of tree. But this would come at a loss in biodiversity. (And the clearing of the mature forest might also liberate more $\mathrm{CO}_{2}$ than the new forest sequesters, depending on the soil type and on what is done with the cleared wood.) The Kyoto Protocol gives credit for afforestation but not for conserving existing forests against deforestation, hence exacerbating this risk. Efforts to give credit for conserving existing forests, such as through the system of Compensation for Avoided Deforestation proposed by the Coalition of Rainforest Nations (and the similar earlier proposal in the Forests for the Future Initiative of 1992-93), are a promising approach to curing this flaw.

$>$ Some pollutants have a cooling effect. "Anthropogenic contributions to aerosols... together produce a cooling effect," and, "volcanic and anthropogenic aerosols have offset some warming that would otherwise have taken place." Current air pollution laws seek to reduce these pollutants -in order to protect public health against inhalation - typically without considering the adverse effect such reductions will have on global warming. ${ }^{43}$ The

.41 Wiener, Protecting the Global Environment, supra note 39, at 198-201. The Kyoto Protocol includes HFCs in its Annex A, and U.S. CAA section 612 gives EPA the authority to regulate CFC-substitutes to "reduce overall risk," so HFCs posing a global warming risk could be regulated under that authority.

42 IPCC WORKING GROUP I CONTRIBUTION TO THE FOURTH ASSESSMENT RePORT, Climate ChaNGe 2007: THE PHYSICAL SCIENCE BASIS, SUMMARY FOR POLICYMAKERS, supra note 1 , at 3,8 .

${ }^{43}$ A recent National Academy panel urged integrating these effects into an overall evaluation:

Policies designed to manage air pollution and land use may be associated with unintended impacts on climate. Increasing evidence of health effects makes it likely that aerosols and ozone will be the targets of stricter regulations in the future. To date, control strategies have not considered the potential climatic implications of emissions reductions. 
solution here is not to pump more sulfate aerosols into the air while ignoring their adverse effects on public health, nor to reduce their emissions while ignoring the adverse effect on global warming; it is to recognize the risk-risk tradeoff and take both effects into consideration. ${ }^{44}$

$>$ Various geoengineering approaches have been identified to forestall global warming if emissions limits turn out to be inadequate or too late. These geoengineering options include adding aerosol particles to the upper atmosphere to reflect incoming solar radiation, or fertilizing plankton in the oceans to soak up more $\mathrm{CO}_{2}$ from the atmosphere, or stationing systems of mirrors in space to reflect incoming solar radiation. Each such proposal needs to be evaluated for the risk-risk tradeoffs it may entail. Some uses of geoengineering may be governed by current environmental law such as the Ocean Dumping Act and related international treaties, the UN Convention on the Law of the Sea, the Environmental Modification Treaty (barring "hostile" environmental modification), and the treaties on satellite orbits, the Moon and Outer Space.

$>$ Carbon capture and storage systems require some place to store the carbon, such as deep well injections and caverns; these storage sites could turn out to leak, gradually undoing some of their $\mathrm{CO}_{2}$ sequestration benefits, or even abruptly leaking large amounts and thereby asphyxiating local biota or posing seismic stress. ${ }^{45}$ These deep storage sites may be

Regulations targeting black carbon emissions or ozone precursors would have combined benefits for public health and climate. However, because some aerosols have a negative radiative forcing, reducing their concentrations could actually increase radiative warming. ... PRIORITY . RECOMMENDATIONS: Apply climate models to the investigation of scenarios in which aerosols are significantly reduced over the next 10 to 20 years and for a range of cloud microphysics parameterizations. Integrate climate forcing criteria in the development of future policies for air pollution control and land management.

COMM. ON RADIATIVE FORCING EFFECTS ON ClIMATE, supra note 1, at 10.

${ }^{44}$ For one effort to incorporate such multiple conflicting effects into a full analysis, see Ronald G. PRINN ET AL., MIT JoInt PROGRAM ON SCIENCE AND Policy of Global Change, Effects of Air Pollution Control on Climate, Report No. 118 (2005), available at http://web.mit.edu/globalchange/www/ MITJPSPGC_Rpt118.pdf.

45 See Working Group III, Intergovernmental Panel on Climate Change, IPCC Special Report: Carbon CAPTURE and Storage, Summary 
regulated under current environmental laws governing underground waste injection, oil and gas extraction, and safe drinking water; EPA is currently developing a regulation on underground carbon storage pursuant to the SDWA. ${ }^{46}$

At the same time, successfully addressing climate change could produce significant ancillary co-benefits, such as:

$>$ Reductions in $\mathrm{CO}_{2}$ emissions (and other GHG emissions such as black carbon ${ }^{47}$ ), if achieved by reducing combustion of fossil fuels (especially coal, and a shift to energy conservation or to alternative energy sources such as nuclear or solar), would likely mean public health cobenefits in reduced emissions of other pollutants associated with fossil fuel combustion. Air pollution from coal combustion, such as sulfur dioxide $\left(\mathrm{SO}_{2}\right)$ and nitrogen oxides, is estimated to take thousands of lives per year in the U.S., and in China; due to these public health effects alone, without considering the climate effects, studies find that coal-fired combustion is significantly underpriced. ${ }^{48}$ Oil spills from tanker ships and pipelines might also decline if oil were used less for motor vehicles and home heating. Over time, a strong and sustained climate policy might eventually render superfluous major provisions of the current CAA, Oil Pollution Act, and other statutes that address the residuals of fossil fuel combustion (while perhaps introducing, as noted above, the need for new laws to deal with the new risks posed by new energy systems).

$>$ Note that if climate policy involves measures that do not reduce fossil fuel combustion-such as geoengineering, or

FOR POLICYMAKERS 12-15 (2005).

${ }_{46}$ See 73 Fed. Reg. 43,492 (July 25, 2008).

47 See V. Ramanathan \& G. Carmichael, Global and Regional Climate Changes due to Black Carbon, 1 NATURE GEOSCIENCE 221, 226 (2008) (finding that black carbon has a significantly greater influence on radiative forcing than earlier estimates, and observing that reductions in black carbon could yield major public health benefits, especially in China, India and other developing countries).

48 See H. Spencer Banzhaf, Dallas Burtraw \& Karen Palmer, Efficient Emission Fees in the U.S. Electricity Sector, 26 RESOURCE AND ENERGY ECONOMICS 317 (2004) (finding that the price of coal would be much higher, and higher than other fuels, if the full social, health and environmental costs of each fuel were internalized in the price system). 
major expansion of sinks, or carbon capture \& storage (without affecting other pollutants) from coal-fired power plants-then these co-benefits in reduced conventional pollutants may not occur.

$>$ Credit for avoided deforestation could provide a major stimulus for biodiversity conservation, while also reducing the costs of GHG abatement. ${ }^{49}$

$>$ Other ancillary benefits of climate policy could include, for example, reduced traffic fatalities as mass transit substitutes for automobiles, and improved cardiovascular health and social capital as housing clustered near mass transit routes substitutes for sprawl.

The solution to these risk-risk tradeoffs, such as cross-gas and cross-sector shifts, is not to give up on GHG regulation. Both ancillary harms (countervailing risks) and ancillary benefits can be addressed through the design and scope of the regulatory system. First, the scope of the regulatory system should internalize the externalities of regulation. ${ }^{50}$ Regulating more comprehensively, by covering all the major GHGs and economic sectors in the regulatory system, is environmentally superior because it matches the scope of the climate problem, avoids perverse cross-gas and cross-sector shifts, and encourages conservation of forest sinks. ${ }^{51}$ It may also encourage more co-benefits from reduction of GHGs such as black carbon that also pose local public health impacts. ${ }^{52}$ And it is economically superior because it offers the flexibility to

49 See Jonathan B. Wiener, Making Markets for Global Forests Conservation, in PaINTING THE WhITE HOUSE GREEN: RATIONALIZING Environmental Policy Inside the Executive Office of THE President (Randall Lutter \& Jason F. Shogren eds., 2004); Massimo Tavoni, Brent Sohngen \& Valentina Bossetti, Forestry and the Carbon Market Response to Stabilize Climate, 35 ENERGY POLICY 5346 (2007).

50 See BUCHANAN \& TULLOCK, supra note 14.

51 See Reconstructing Climate Policy, supra note 2; Stewart \& Wiener, supra note 8; Wiener, Protecting the Global Environment, supra note 39, at 193225.

52 See James Hansen et al., Global warming in the twenty-first century: An alternative scenario, 97 PROCEEDINGS OF THE NATIONAL ACADEMY OF SCIENCES 9875-80 (no. 18) (2000), available at http://www.pnas.org/content/97/18/ 9875.full.pdf+html; Ramanathan \& Carmichael, supra note 47. Note that black carbon is not yet included in the Kyoto Protocol, Annex A, list of regulated GHGs, but could be added in the future. Annex A to the Kyoto Protocol to the United Nations Framework Convention on Climate Change, Dec. 10, 1997, 37 I.L.M. 22 (entered into force Feb. 16, 2005). 
choose the least-cost abatement opportunities across all GHGs and sectors. $^{53}$

The FCCC and the Kyoto Protocol made progress in this direction, covering most major GHGs and all sectors, despite opposition from the EU which preferred a $\mathrm{CO}_{2}$-only approach. ${ }^{54}$ The EU Emissions Trading System went back to covering $\mathrm{CO}_{2}$ only in its pilot phase (2005-07), while promising to broaden its scope to address other GHGs in subsequent phases. Several of the major bills pending in the U.S. Congress would cover most GHGs and most sectors, though some omit agriculture and forests. U.S. policy could lead the way to a more fully comprehensive scope for global climate policy.

Second, the adoption of climate policy should take account of risk-risk tradeoffs through impact assessments. As noted above, this is already required under FCCC article 4(1)(f). In the U.S., it is also required under Executive Order 12866 and its guidelines; in Europe this is required under the Impact Assessment Guidelines (discussed further in the next section of this article). One improvement in the U.S. approach would be for Congress itself to consider risk-risk tradeoffs when enacting new climate legislation (as is done in Europe), rather than leaving that step only to the federal agencies when they promulgate rules implementing legislative instructions.

\section{B. Benefit-Cost}

Benefit-cost tradeoffs should also be considered in making climate policy. But they may not always be cognizable under current U.S. law. For example, under the CAA, EPA must set the NAAQS without considering cost. ${ }^{55}$ This condition is curious enough for conventional pollutants-how can the agency decide how much pollution control is enough? The statute says EPA

53 See Reconstructing Climate Policy, supra note 2 ; J. Reilly et al., The Role of Non-CO${ }_{2}$ GHGs in Climate Policy: Analysis Using the MIT IGSM, special issue 3 THE ENERGY JOURNAL 503 (2006), available at http://mit.edu/globalchange/www/MITJPSPGC_Reprint06-10.pdf; John Reilly et al., Multi-gas Assessment of the Kyoto Protocol, 401 NATURE 549, 551 (1999) (finding a $60 \%$ reduction in cost from a comprehensive multi-gas policy compared to a $\mathrm{CO}_{2}$-only policy).

54 See Wiener, Something Borrowed, supra note 11, at 1308-09.

55 Whitman v. Am. Trucking Assns., 531 U.S. 457 (2001). 
should choose the level "requisite to protect the public health," but public health is affected to some degree at any pollution level, more or less; the question is how healthy, how much pollution control. $^{56}$ Or, put another way, why should EPA ever set the NAAQS above zero (or above the background level), when a tighter (toward zero) NAAQS would save some additional people from some exposure? The answer must be that something else society values would be sacrificed by tightening the standard further; ${ }^{57}$ EPA, however, is not permitted to acknowledge this. ${ }^{58}$ The prohibition on considering costs in setting NAAQS is a prime example of the obstacles to candid recognition of tradeoffs that are embedded in much current environmental law. Unable to compare costs and benefits forthrightly, the agency avoids regulating, ${ }^{59}$ or conceals its consideration of costs and benefits while asserting other rationales, or distorts and corrupts the science in order to try to justify a decision to set the NAAQS at a positive level. ${ }^{60}$

Even if this cost-blind approach were warranted for conventional pollutants, however, it is clearly inappropriate for climate change. The economic cost of restricting GHG emissions could be quite high, depending on the stringency and type of policy instrument employed. Indeed, the FCCC directs its parties

56 See id. at 490-96 (Breyer, J., concurring). The degree and direction of the effect on health at low doses will depend on the shape of the dose-response function (e.g., linear, threshold, or hormetic).

57 Sensible environmental groups recognize this. For example, commenting on the latest tightening of the ozone NAAQS, even while urging them to be tighter: "John M. Balbus, a physician and the chief health scientist at the Environmental Defense Fund, said, 'Clearly at some point you get to a level where additional benefits just aren't worth it, but I don't think we're there at 75." Matthew L. Wald, Environmental Agency Tightens Smog Standards, N.Y. TIMES, March 13, 2008, available at http://www.nytimes.com/2008/03/13/ washington/13enviro.html.

58 American Trucking, 531 U.S. at 471 n.4 (if .EPA were "secretly considering the costs of attainment... it would be grounds for vacating the NAAQS").

59 See John M. Mendeloff, The Dilemma of Toxic Substance REgulation: How OverREgulation CAUSES UNDERREGUlation at OSHA (2003). This may be one reason that EPA has been reluctant to regulate $\mathrm{CO}_{2}$ under the CAA: knowing that cost could not be considered under key parts of the law, the agency may have sought to avoid getting started. If so, allowing consideration of cost could encourage, rather than discourage (as is often feared), some regulation.

60 See Cary Coglianese \& Gary Marchant, Shifting Sands: The Limits of Sciencè in Setting Risk Standards, 152 U. Pa. L. Rev. 1255 (2004). 
(of which the U.S. is one) to consider cost: it makes clear in Article 2 that while achieving its objective of avoiding dangerous climate change, parties must "ensure that food production is not threatened and ... enable economic development to proceed in a sustainable manner." It provides in Article 3(3) that "policies and measures to deal with climate change should be cost-effective so as to ensure global benefits at the lowest possible cost." And in Article 4(1)(f), quoted above, the FCCC calls for "impact assessments" or similar methods to "minimize the adverse effects on the economy" of climate policy.

At the national level, both the U.S. and European regulatory systems have espoused routine application of benefit-cost analysis in regulatory impact analyses. ${ }^{61}$ Every U.S. President since Jimmy Carter has required economic analysis of new regulations. This paper is not the place (nor is there space here) to mount a full explanation and defense of a sensible version of benefit-cost decision making, but it should at least be clear that sound decision making on climate change policy requires consideration of the important social consequences of each option. ${ }^{62}$ Even advocates of stringent regulation of GHG emissions have, generally, not argued that costs should be ignored; rather, they have argued that the benefits (avoided damages) from climate policy exceed the costs and therefore justify regulations. ${ }^{63}$

61 Jonathan B. Wiener, Better Regulation in Europe, 59 CURRENT LEGAL PROBS. 447 (2006).

62 The science of climate change is necessary but insufficient to make policy choices, because those policy choices also depend on value judgments about how much risk is acceptable given that further risk reduction would entail sacrifices in other social objectives. Thus, the debate over whether global warming is "real" or not has been asking the wrong question. A complex future problem like climate change is neither "real" nor "false," but is probabilistic and uncertain. Uncertainty does not necessarily warrant inaction about such a risk; it often makes sense to purchase insurance against uncertain risks, as we have done for accidents, fires, a Soviet nuclear missile attack, and other uncertain risks. Taking uncertainty into account, a well-designed low-cost climate policy can be desirable. On the other hand, certainty (saying it's "real") would not necessarily warrant drastic action; it would still make sense to weigh the benefits against the costs to choose the best options.

${ }^{63}$ One exception is Douglas Kysar, Climate Change, Cultural Transformation, and Comprehensive Rationality, 31 B.C. ENVTL AFF. L. REV. 555 (2004) (advocating cultural transformation toward an environmental ethic to combat climate change, and arguing against comparison of costs and benefits in climate policy). But effective policy action to prevent climate change through 
By benefit-cost analysis (BCA), I do not mean a strict quantified optimization that omits important but unquantified benefits. Rather, BCA should mean a "warm" or "soft" guide to informing decisions that helps decision makers ensure they consider all important consequences of policy choices. ${ }^{64}$ It should inform rather than dictate public regulatory decisions. And in the case of climate change, applying BCA does not necessarily favor watering down or restraining the policy response. Indeed it can mean strengthening climate policy. Whereas some analysts see modest benefits to climate policy, ${ }^{65}$ others see high benefits (especially due to potential low-probability high-consequence catastrophic impacts). ${ }^{66}$ Moreover, a policy guided by BCA can chart a path of optimal emissions over the next few decades that involves more stringent policy limits than does the emissions path of a "least-cost" strategy to stabilize atmospheric GHG concentrations at a specified level such as $550 \mathrm{ppm}$, because the $\mathrm{BCA}$ path gives weight to the interim damages from ongoing climate change whereas the least-cost path to stabilization does not. ${ }^{67}$

The upshot is that an integrated approach to U.S. climate change policy, recognizing cross-cutting issues and tradeoffs, will best be accomplished through new legislation that encompasses all major GHGs and all sectors of the economy, and gives credit for protection of sinks. It should attend to risk-risk and benefit-cost tradeoffs within the climate policy design itself through

GHG emissions reductions may be needed long before such a cultural transformation could unfold. Moreover, a cultural transformation in the U.S. may not influence China's policies and global GHG emissions trajectories. Consequentialist analysis and incentives are more likely to engage the U.S. and China in effective climate policy. See Jonathan B. Wiener, Climate Change Policy and Policy Change in China, 55 UCLA L. Rev. 1805 (2008).

${ }^{64}$ See Wiener, Better Regulation in Europe, supra note 61 (advocating "warm analysis" of the kind espoused by Benjamin Franklin).

${ }^{65}$ See, e.g., BJORN LOMBORG, COOL IT: THE SECULAR ENVIRONMENTALIST'S GUIDE TO GLOBAL WARMING (2007).

66 See, e.g., Richard A. POSNER, CATASTROPHE: Risk AND RESPONSE (2004); MARTIN WEITZMAN, ON MODELING AND INTERPRETING THE ECONOMICS OF CATASTROPHIC Climate CHANGE (2008), available at http://www.economics.harvard.edu/faculty/weitzman/files/modeling.pdf.

67 See ReCONSTRUCTING Climate POLICY, supra note 2; James K. Hammitt, Evaluation Endpoints and Climate Policy: Atmospheric Stabilization, BenefitCost Analysis, and Near-Term Greenhouse-Gas Emissions, 41 ClimatiC CHANGE 447 (1999). 
comprehensive coverage and instructions to reduce overall risk, and via surrounding legal measures such as ex ante and ex post impact assessment of proposed policies (e.g. NEPA and OMB regulatory review). The basic benefit-cost judgment about the level of emissions to allow (through a cap-and-trade or tax instrument) should initially be made by Congress (rather than delegated to EPA), as it was in the Acid Rain Trading Program of the 1990 CAA. $^{68}$ This put the main question of social tradeoffs in the hands of Congress, rather than delegating the policy objective to the agency as many current environmental laws have done. ${ }^{69}$ But Congress is not institutionally well-equipped to conduct or rely on $\mathrm{BCA}$, and when setting goals (such as the allowance cap) for climate policy, it should be informed in this judgment by experts' impact assessments (as is now done in the EU). Individual members of Congress often request such impact assessments from relevant agencies, such as EPA and DOE; perhaps the General Accountability Office (GAO) or Congressional Budget Office (CBO) could beef up its capacity to serve Congress more consistently and coherently in conducting impact assessments of major pending legislation.

In climate policy, an adaptive management approach to benefit-cost tradeoffs could be implemented through multi-year targets combined with periodic revision. Congress could set a

${ }^{68}$ In 1990 , Congress set two phases of $\mathrm{SO}_{2}$ allowance caps during the next decade. Clean Air Act of 1990, Pub. Law. 101-549 §§ 404-405 (1990). Later, EPA effectively tightened the cap further in its Clean Air Interstate Rule (CAIR) issued in 2005. CAIR was invalidated by the D.C. Circuit on July 11, 2008. See North Carolina v. E.P.A., No. 05-1244 (D.C. Cir. 2008).

${ }^{69}$ See DAVID SChOENBROD, POWER Without REsPONSIBILITY: How Congress Abuses the People Through Delegation (Yale Univ. Press, 1993) (critiquing Congressional delegation to agencies); Bruce Ackerman \& Richard B. Stewart, Reforming Environmental Law: The Democratic Case for Market Incentives, 13 CoLUM. J. ENVT'L L. 171 (1988) (arguing that market-based incentives will put the question of the social objective - the aggregate level of pollution-before Congress, rather than concealing it in agency decisions on each rulemaking); David Schoenbrod, Delegation and Democracy: A Reply to my Critics, 20 CARDozo L. REV. 731 (1999). Lisa Heinzerling argues in Selling Pollution, Forcing Democracy, 14 STAN. ENVTL. L. REV. 300 (1995) that Congress did not actually confront the social objective question in its deliberations over the acid rain emissions trading program in the 1990 CAA amendments, but she neglects the evidence that Congress weighed costs in choosing among different caps on $\mathrm{SO}_{2}$ emissions. To be sure, Congress could benefit from enhanced institutional support to conduct impact assessments of pending legislation. 
multi-year schedule of declining caps on emissions over the coming decades, and then direct itself, or call on an expert body (such as EPA, or OMB, or a new "Carbon Fed" modeled after the apolitical Federal Reserve Bank), to review and adjust the schedule over time as new information warrants, in light of benefit-cost analyses, perhaps including regular reviews conducted by the National Academy of Sciences. This approach could serve both the objectives of containing costs and attaining the environmental benefits being sought as information and understanding improve over time. Of course, Congress itself could always amend or repeal its climate legislation, but too easy resort to wholesale changes would undermine the incentives for investors to develop and adopt low-GHG technologies. Setting a longer-term multiyear schedule of emissions limits (rather than a one-time near-term target) will give a more credible signal to investors to promote innovation and diffusion. Climate is a complex problem where learning over time will surely inform sequential adjustments in that long-term schedule. Giving the lead role (though always subject to amendment by Congress), or at least an advisory role, on any subsequent revisions to an expert body like EPA, OMB or a Carbon Fed (or all three in collaboration), informed by BCA, would harness the relevant expertise that Congress itself lacks, confront important tradeoffs in a transparent setting, and sustain investors' confidence in the future of the policy and the market. In addition, as U.S. climate change policy is enacted and implemented, impact assessment using BCA (as defined above) should be applied to each act of Congress, and (as is now routine) to each major agency rulemaking.

Perhaps climate policy, by showing the need for integrated cross-sectoral approaches that candidly confront risk-risk and benefit-cost tradeoffs, will also stimulate reform of these features of current environmental law. For example, climate policy may integrate agriculture and forestry into an economy-wide regime, in light of the low-cost GHG abatement opportunities in those sectors, the concern (noted above) that GHG emissions could shift (leak) to farms if production of crop-based fuels such as ethanol were unregulated, and the need to persuade key developing countries to include agriculture and forests in their baselines and 
emissions limits. ${ }^{70}$

Alternatively, lawmakers may be glad to adopt these improved approaches in a new climate policy, but reluctant to reopen settled questions in past laws. Revision of past laws will be more likely if climate policy increases the benefits of doing so or lowers its costs. For example, if climate policy results in the development of new methods to monitor GHG emissions from non-point area sources, those monitoring methods could then make it attractive to apply them to conventional pollution from farms.

\section{INCENTIVES}

Perhaps the most remarkable change in environmental law over the past three decades has been the shift from acrimony toward consensus over market-based economic incentive instruments such as cap and trade. Climate policy should make use of these incentive instruments because, by allowing flexibility in how and where emissions are reduced (and in some programs, when they are reduced, via banking and borrowing), these policy design features significantly reduce the cost of abatement and enhance the stimuli for innovation. Studies find that full allowance trading can reduce the cost of GHG abatement by half or more compared to no-trading scenarios. ${ }^{71}$ And because GHGs mix globally in the atmosphere, with essentially no local effects, the concern that allowance trading may yield hotspots of excessive local damage is not significant for GHGs.

A generation ago, the debate raged between advocates of command-and-control technology standards and advocates of market-based incentives. Today that question has largely been

70 If climate policy achieves this cross-sectoral integration, that could show the way to doing the same in conventional Clean Water Act pollution policy (where non-point sources such as farms have traditionally been left out of regulations applied to industry).

71 See Reconstructing Climate Policy, supra note 2. Together with the 60 percent or greater cost reduction associated with comprehensive multi-gas policy, see Reilly et al., Multi-Gas Assessment, supra note 53, the $50 \%$ or greater cost reduction from emissions trading would yield an $80 \%$ or greater cost reduction for a comprehensive multi-gas cap-and-trade policy as compared to fixed $\mathrm{CO}_{2}$-only emissions limits with no trading. See id. Publicizing and explaining this dramatic effect of improved policy design may be needed to help break the logjam confronting new environmental laws, as discussed in the introductory section of this article. 
settled with broad acceptance of incentive instruments, while recognizing that they will not be superior in every case. A key factor in this change was the $\mathrm{SO}_{2}$ allowance trading system to control acid rain (designed by the first Bush administration in 1989-90, in collaboration with the Environmental Defense Fund), its bipartisan enactment by Congress in the 1990 CAA amendments, and the subsequent success of that program: it reduced emissions faster than expected, at far lower costs. ${ }^{72}$

At about the same time, in 1990-92, the U.S. advocated the inclusion of market-based emissions trading in a climate regime, though some in the U.S. government resisted a binding cap. ${ }^{73}$ In these early years of climate negotiations, the EU was opposed to trading. In the Clinton administration, the U.S. continued its advocacy of emissions trading, now with explicit support for a quantitative cap (target) on emissions. Despite EU resistance to trading, the U.S. obtained a short paragraph authorizing international emissions trading in Article 17 of the Kyoto Protocol in 1997, but without spelling out how the system would work. The EU still sought to constrain that policy option through restrictions on how much a country could satisfy its target through trading (inserting the term "supplemental" in Article 17) and other criteria.

But after the new President Bush withdrew the U.S. from Kyoto in 2001, and because the EU needed to persuade Russia to ratify for the Kyoto Protocol to enter into force, the EU then changed its mind, and began to favor market-based incentives. The EU Emissions Trading System (ETS), launched in 2004, is now the largest such cap and trade system in the world.

Meanwhile, in the U.S. the major environmental groups, formerly sharply divided on this question, now appear to agree that a cap and trade approach would be ideal to limit GHG emissions. And major corporations, seeing climate legislation on the horizon, are beginning to publicly endorse cap and trade as a low-cost method. All the major bills currently pending in the U.S. Congress would launch cap and trade systems. ${ }^{74}$

72 See Denny Ellerman et al, Markets for Clean Air: The U.S. ACID RAIN PROGRAM (2000).

73 See Wiener, Something Borrowed, supra note 11 (recounting the early history of U.S. support for a cap-and-trade system for GHGs).

74 On the roles of interest groups and rent-seeking in climate change law, see Jonathan B. Wiener, On the Political Economy of Global Environmental 
The current debate in the U.S. regarding climate policy instrument choice is not the old argument about command-andcontrol technology standards versus market-based incentives, but rather the new contest between two types of market-based incentives, trading and taxes.

In principle, taxes and allowance trading instruments can achieve nearly identical results, but there are some key differences. First, GHG taxes raise revenue which can be used to offset other distortionary taxes (such as taxes on income to labor and capital) and thereby reap a "double dividend" from "revenue recycling."75 But cap and trade can generate the same revenues if allowances are sold (auctioned) rather than issued for free.

Second, under uncertainty about true costs of abatement, a tax limits the price of controlling emissions (but might let emissions rise) whereas an allowance system limits the quantity of emissions (but might let the price of controlling emissions rise). Which instrument is preferable depends on the relative harm from emissions rising versus the harm from prices rising. ${ }^{76}$ Some economists favor GHG taxes over allowances on this ground, arguing that price increases impose more sharply rising harms whereas emissions increases only gradually add to the stock of atmospheric GHG concentrations and thus pose only gradually rising harms. ${ }^{77}$ But if rising GHG concentrations were approaching an abrupt threshold of sharply increasing harm, then emissions escalation might pose more extreme harms than cost

Regulation, 87 GEO. L.J. 749 (1999). On the recent realignment of interest groups to support cap and trade for GHGs in the Congress, see DeShazo \& Freeman, supra note 9.

75 See A. Lars Bovenberg \& Ruud A. de Mooij, Environmental Levies and Distortionary Taxation, 84 Am. Econ. Rev. 1085, 1085 (1994); Lawrence H. Goulder, Environmental Taxation and the "Double Dividend": A Reader's Guide, 2 Int'l Tax \& Pub. Fin. 157 (1995); Ian W.H. Parry, Lawrence H. Goulder \& Dallas Burtraw, Revenue-Raising Versus Other Approaches to Environmental Protection: The Critical Significance of Preexisting Tax Distortions, 28 RAND J. ECON. 708 (1997); Ian W.H. Parry, Pollution Taxes and Revenue Recycling, $29 \mathrm{~J}$. ENVTL. ECON. \& MGMT. S64, S65 (1995).

${ }^{76}$ See Martin L. Weitzman, Prices versus Quantities, 41 REV. ECON. STUD. 477 (1974).

77 See LaN W.H. ParRy \& WILLIAM A. Pizer, Emissions Trading vS. $\mathrm{CO}_{2}$ TAXES VS. STANDARDS (2007), available at http://www.rff.org/rff/ Publications/upload/31809_1.pdf; William A. Pizer, Combining Price and Quantity Controls to Mitigate Global Climate Change, 85 J. Public Econ. 409 (2002). 
escalation. In any case, allowance trading systems can be designed to contain costs, such as through (i) trading across time periods (cumulative multiyear target periods, banking, and borrowing), (ii) a broader trading market (linking to international trading markets and to offsets in other sectors), (iii) a "safety valve" in which the government sells additional allowances at a pre-set trigger price (essentially converting the cap and trade system into a tax at that price; this trigger price might be set to increase slightly each year, and the revenues could be dedicated to purchasing GHG emissions abatement), ${ }^{78}$ or (iv) an allowance reserve (in effect, a safety valve with a finite quantity of additional permits to be sold at the trigger price). ${ }^{79}$ Through these kinds of design features, a cap-and-trade system can moderate uncertainty about its costs.

Third, allowance systems can be designed to engage participation by reluctant parties, through allocation of headroom allowances that can then be sold in the market. This form of side payment is the way that the U.S. acid rain $\mathrm{SO}_{2}$ trading program was designed to assure adoption in Congress, the way the Kyoto Protocol engaged Russia, and the way that the EU allocated burdens in its Emissions Trading System so as to succeed in engaging all its member states (after being unable to succeed in getting member states to agree to an EU carbon tax). ${ }^{80}$ It can also be a way to engage China, India and other major developing countries in a post-Kyoto regime. Such side payments are especially crucial at the international level where participation in a treaty requires the consent of each country. ${ }^{81}$ Within the U.S.,

${ }^{78}$ On these cost containment features to reduce price uncertainty in a cap and trade system, see Stavins, supra note 8, at 315-16, 352; Pizer, supra note 77.

79 See Brian C. Murray, Richard G. Newell \& William A. Pizer, BALANCING COST AND EMISSIONS CERTAINTY: AN ALLOWANCE RESERVE FOR CAP-AND-TRADE (Duke University 2008), available at http://www.nicholas.duke.edu/institute/wp-costemissions.pdf. The allowance reserve, like the safety valve, could operate automatically when the market price rises to hit the previously selected trigger price; or perhaps the allowance reserve (or other cost containment mechanisms) could be managed by a "Carbon Fed" board with the power to authorize additional allowance sales or greater use of offset credits, or otherwise moderate prices. Id.

80 See Frank CONVERy, DenNy Ellerman \& Christian DE PERTHUIS, ThE EUROPEAN CARBON MARKET IN ACTION: LESSONS FROM THE FIRST TRADING PERIOD - INTERIM REPORT (2008), available at http://www.aprec.net/documents/08-03-25_interim_report_en.pdf.

81 See Wiener, Global Environmental Regulation, supra note 8; RECONSTRUCTING CLIMATE POLICY, supra note 2. 
studies suggest that an allowance allocation of just 10 to 15 percent (if information on firms' burdens is not difficult to obtain) could be sufficient to fully compensate the hardest-hit firms, ${ }^{82}$ and just part of that amount may be all that is needed to overcome their political opposition sufficiently to ensure adoption. A tax, by contrast, is unlikely to attract participation by major emitting countries who see abatement costs but few climate benefits. Trying to combine the tax with a side-payment to the country being taxed could undermine the incentive effect of the tax on emissions (a problem solved by the allowance cap) ${ }^{83}$ In addition, at the international level, countries could adopt GHG taxes but simultaneously modify other internal fiscal policies (taxes or subsidies) to cushion the effect of the GHG tax on their economies, thus vitiating the GHG tax in a way that is difficult for the international community to monitor and deter; a cap-and-trade system solves this problem by limiting aggregate emissions irrespective of internal fiscal maneuvering. ${ }^{84}$ Thus, in general, the choice of instrument relates directly to the question of scale (addressed in the next section), and in particular, an international cap-and-trade system is likely to be superior to an international tax.

The current debate also addresses particular elements of a trading system, including:

$>$ how stringent a cap to set, and over what time period,

$>$ which sectors to cover (economy-wide, or electric power,

${ }^{82}$. See Stavins, supra note 8, at 320-21; Dallas BURTRAW \& KarEN PALMER, COMPENSATION RULES FOR Climate POLICY IN THE EleCTRICITY SECTOR, RFF DISCUSSION PAPER 07-41 (July 2007); A. Lans Bovenberg \& Lawrence $\mathrm{H}$. Goulder, Neutralizing the Adverse Industry Impacts of $\mathrm{CO}_{2}$ Abatement Policies: What Does It Cost?, in BEHAVIORAL AND DisTRIBUTIONAL EFFECTs of ENVIRONMENTAL POLICY (Carlo Carraro and Gilbert Metcalf, eds., University of Chicago Press, 2001).

${ }^{83}$ For more detail on participation and the efficacy of allowance trading versus taxes, see ReCONSTRUCTING Climate PoliCy, supra note 2; Wiener, Global Environmental Regulation, supra note 8.

${ }^{84}$ See Wiener, Global Environmental Regulation, supra note 8, at 785-87 (identifying the problem of "fiscal cushioning" in international climate policy and explaining that it is easier to solve under a cap-and-trade system than under a tax); $c f$. JOSEPH ALDY, EDUARDO LEY \& IAN PARRY, A TAX-BASED APPROACH TO Slowing Global Climate Change, RFF Discussion Paper 08-26, at 26-28 (2008) (proposing complex monitoring regimes to try to salvage an international GHG tax from fiscal cushioning), available at http://www.rff.org/RFF/Documents/RFF-DP-08-26.pdf 
industry, transportation, agriculture, forests),

$>$ allocation (whether allowances would be issued for free or auctioned, or some of each, as discussed above; and whether credit should be given for early abatement efforts),

$>$ cost containment (such as a "safety valve" maximum allowance price at which the government would sell unlimited additional allowances, a limited quantity reserve of additional allowances, or a "Carbon Fed" oversight board to manage the allowance market),

$>$ international competitiveness provisions (such as border taxes or border allowance requirements on imports from countries without caps),

$>$ the availability of "offset" credits from unregulated sectors (e.g., agriculture) and from international abatement projects.

Ideally, the U.S. approach would be economy-wide, thus avoiding cross-sector leakage and harnessing the most costeffective abatement opportunities across the U.S. economy. The broad coverage and widely-radiating influence of putting a price on GHG emissions would obviate the detailed industry-specific technical standards that have been typical of much past environmental law. ${ }^{85}$ An economy-wide scope would also make unnecessary the criteria and monitoring for "offset" credits in unregulated sectors (though offset credits for carbon storage in

85 One possible impediment to the success of a cap-and-trade system or a tax in reducing actual emissions could be institutional barriers to the influence of price signals on emitting activities. In some cases, firms and households may not reduce emissions much despite an increased price of emitting under the trading or tax policy. For example, emissions in the electric power sector may be highly responsive (elastic) to such price changes, but emissions from transportation and buildings may be more inelastic because people's choices of which car and house to own, and which neighborhood to live in (at a distance from work, schools and shopping), are difficult to change in a short time. New energy-efficient buildings and mass transit systems may take a long time to build and to link to patterns of daily travel. If so, reducing emissions from transportation may warrant changes in technical standards, and land use policies at the state and local level, to complement national GHG emissions allowances or taxes. But technical energy efficiency standards may raise costs, may perversely encourage greater use and hence a rebound in emissions, and may discourage replacement of old equipment with new equipment. See Stavins, supra note 8, at 328, 345-48. Other institutional barriers such as subsidies for resource use may also conflict with GHG reduction incentives; removing such subsidies could be both environmentally and economically desirable. 
biological and geological repositories would still be needed) ${ }^{86}$ Although measuring emissions and sink sequestration in some sectors (such as agriculture) may be more costly than the measurement of emissions from the energy sector, that difference in measurement cost will likely be dwarfed by the environmental benefits and social cost savings of encompassing all sectors. And the measurement task is endogenous-a function of incentives provided for improved measurement approaches-and it can be eased by using default measurement values that can be adjusted if firms present more accurate and reliable measurement information. ${ }^{87}$

The U.S. approach should be part of a global regime (or set of plurilateral regimes) that engages all major emitting countries. This point is elaborated in the next section on Scale, below. Such a global cap-and-trade regime would encompass a much larger share of global emissions, avoid international leakage, harness the most cost-effective abatement opportunities worldwide, and inhibit exercise of market power in the allowance market. Moreover, it would make unnecessary the border tariffs or other policies being considered to mitigate the international competitiveness risks of a U.S.-only policy. If the U.S. Congress enacts major climate legislation in 2009 before a post-Kyoto global regime is fully worked out, any such border tariffs should be applied evenhandedly with domestic regulations to avoid WTO invalidity. ${ }^{88}$ Another way to help engage major developing

${ }^{86}$ Stavins, supra note 8 , advocates an upstream cap-and-trade system that would cover most of the U.S. economy, with offsets for carbon storage in biological and geological sinks. But he omits non- $\mathrm{CO}_{2}$ GHGs and emissions from sectors such as agriculture where they are not related to fossil fuel use (e.g. nitrous oxide emissions from agricultural fertilizer). My approach would encompass these gases and sectors in a broader scope.

${ }^{87}$ See Jonathan B. Wiener, Solving the Precautionary Paradox: Policy Approaches to Improve Measurement of Greenhouse Gas Sources and Sinks, in NON-CO ${ }_{2}$ GREENHOUSE GASES 527 (J. van Ham et al., eds., 1994).

${ }^{88}$ See Joost Pauwelyn, U.S. Federal Climate Policy and Competitiveness Concerns: The Limits and Options of International Trade Law (Nicholas Institute for Environmental Policy Solutions, Duke University, Working Paper NI-WP 07-02, 2007). Stavins, supra note 8, at 326-27, advocates a border GHG allowance requirement on GHG-intensive products imported from countries not limiting their GHG emissions, but only beginning 10 years after the U.S. capand-trade policy is launched, in the hopes of thereby pressuring other countries to act along with the U.S. Michael Vandenbergh, Climate Change: The China Problem, 81 S. Cal. L. Rev. 905 (2008), advocates mobilizing U.S. consumers to 
countries in such a global regime would be to embed conditional steps in the U.S. regime: initial action (a cap and declining phases) in the U.S. legislation, with the next steps (tighter cap phases) contingent on some degree of action by other major emitters including developing countries.

To the extent that the "logjam" in U.S. environmental legislation is due to the high cost of enacting additional protective measures, the use of market-based incentives should help overcome that obstacle by offering more environmental protection at less cost. The EU's adoption of its ETS for $\mathrm{CO}_{2}$ may not have been breaking a logjam in European regulation, but it was nonetheless spurred by the need to keep costs low and to distribute burdens fairly among EU member states.

Market-based incentives are also better at stimulating technological innovation than are traditional command-and-control policies. Ironically, "technology-forcing" by government mandate of a specific technology tends to stagnate, not spur technological change. Government is usually behind industry in its awareness of cutting-edge technology. And once government mandates a specific technology, that tends to freeze investment in research and development (R\&D). Market-based incentives, by contrast, give firms a powerful incentive to develop more effective, lower-cost methods to reduce pollution, saving the firm on abatement costs and potentially freeing up excess allowances for sale to other firms. ${ }^{89}$

It may be that successful climate policy will herald the success of market-based incentives in environmental policy more generally. This may be true over a much longer time horizon than the current environmental law era. After five centuries of transition from feudalism (central control of decisions) to markets (decentralized competitive decisions) in land, labor and capital, it is not implausible that climate policy will represent the next stage in that evolution, shifting from centralized control to decentralized

insist on disclosure of the GHG emissions embodied in imports from China.

89 See Adam B. Jaffe et al., Technology Policy for Energy and the Environment, 4 Innovation Policy and the Economy 35 (2003). Government support for basic research may also be needed as a complement to incentives for emissions reductions, see Jaffe, Newell \& Stavins, supra note 8 . But government research alone is insufficient to motivate diffusion and adoption of new technologies, which requires incentives for emissions reductions (a price on GHG emissions) as well. 
flexibility (although subject to a centralized societal constraintthe "cap" in cap and trade) and incorporating ecosystem services into markets in a very big way. After the fall of the Soviet Union and liberalization in China, on the one hand, and the failure of deregulatory zeal in the U.S. on the other, all sides appear to agree that both some regulation is needed and that command requirements do not work as well as market-based incentives. ${ }^{90}$ Whereas environmentalism in the 1970 s portrayed markets and capitalism as the enemy, today environmentalists see markets as flawed but market-based incentives as attractive correctives, reconstituting markets to internalize externalities. ${ }^{91}$ This is especially true for climate, where the costs of the central command approach applied to all activities in the entire economy would be prohibitive, and the concern over hotspots is absent. If so, a successful market-based climate policy could seal the end of the debate between environmentalism vs. capitalism, via a merging or rapprochement. We will all be market-based environmentalists now.

Another result of this change may be that markets in other environmental resources catch on. There are already markets in transferable fishing quotas, and efforts to create markets in ecosystem services. These markets have been successful where variations in the cost of compliance made flexibility across firms attractive. $^{92}$

Moreover, by putting a price on carbon, the new climate policy will affect many other markets. Finance and investment markets will respond by monetizing firms' carbon assets and liabilities, assisted by SEC disclosure requirements. New insurance policies will cover carbon assets, including carbon sequestered in sinks. Real estate transactions will account for the carbon assets or liabilities being transferred. By conferring market value on undeveloped lands (at least those storing carbon), the carbon market will both reward land conservation and reduce the ability of landowners to claim "total" takings under restrictive land

90 For an assessment of progress so far, see Richard B. Stewart, $A$ New Generation of Environmental Regulation?, 29 Cap. U. L. Rev. 21 (2001).

91 See Richard B. Stewart, Reconstitutive Law, 46 Md. L. Rev. 86 (1986).

92 See Katrina Miriam Wyman, From Fur to Fish: Reconsidering the Evolution of Private Property, 80 N.Y.U. L. Rev. 117 (2005) (comparing U.S. and Canadian uses of allowance markets to regulate $\mathrm{SO}_{2}$ and fish catch). 
use regulation. ${ }^{93}$ Because GHG emissions are pervasive in every sector of the economy, a market-based climate policy will radiate its effects through the economy.

\section{SCALE}

Climate change is a global problem: GHG emissions sources and sinks are located in every country, and GHGs mix globally in the atmosphere. As a result, GHG emissions (and abatement measures) anywhere have the same impact on the global climate. The impacts of climate change will also be felt around the world, although in varying ways: for example, warming may be greater near the poles than at the equator, changes in precipitation and disease will vary regionally, and coastal zones will be most affected by sea level rise and storms.

Effective policies to forestall future climate change will require action by at least the major emitting countries, that is, those representing the great majority of current and future emissions. This does not necessarily mean universal agreement among all 190 or so countries in the world, but it does mean that, unlike the Kyoto Protocol, an effective treaty must encompass at least the 15 or 20 largest emitters. These include the U.S.A., China, the European Union, Russia, India, Indonesia, Japan, Canada, Australia, Brazil, Mexico, Korea and South Africa-and ideally joined by others, including countries undergoing significant deforestation.

Broad participation is vital in order to limit global emissions. China's emissions have increased rapidly over the past decade, exceeding forecasts; at the time the Kyoto Protocol was adopted in 1997, China was forecast to surpass the U.S. as the largest $\mathrm{CO}_{2}$ emitter by about 2030 ; by 2006 that forecast date was advanced to 2009; and now it appears that China already passed the U.S. in $2007 .^{94}$ Looking ahead, China's emissions are forecast to grow as

93 As was claimed in Lucas v. South Carolina Coastal Commission, 505 U.S. 1003 (1992). See Maria R. Reff, Reducing Regulatory Takings: Could Carbon Credits Make Undeveloped Land Economically Viable? (Duke University School of Law Independent Study Paper, 2007).

94 See Wiener, Climate Change Policy and Policy Change in China, supra note 63, at 1807-10; INTERNATIONAL ENERGY AGENCY, WORLD ENERGY OUTLOOK 2007 (2007); China to Top USA in Greenhouse Emissions, U.S.A. TODAY, April 28 , 2007, available at 
it relies heavily on coal-fired electric power. If China, India and other developing countries are not engaged in limiting GHG emissions, then stabilizing atmospheric concentrations of GHGs at a level such as $450 \mathrm{ppm}$ (compared to about $380 \mathrm{ppm}$ today, and $275 \mathrm{ppm}$ in the pre-industrial era) looks to be impossible (because emissions from those countries alone, when added to today's concentrations due to prior emissions, will exceed that level); and stabilizing at a higher level such as $550 \mathrm{ppm}$ would be feasible but at much greater cost and with much sharper emissions reductions in the industrialized countries. ${ }^{95}$

Broad participation is also essential to prevent cross-border "leakage" of emitting activities from regulated to unregulated areas. Emissions leakage can occur via relocation of facilities from regulated to unregulated places, and via price changes for goods in world markets (reduced energy demand in one country lowers world prices and increases the quantity consumed elsewhere). Leakage undermines the environmental effectiveness of partial policy actions-at least partially, and possibly even yielding perverse increases in overall emissions. A recent study by the MIT Integrated Assessment model found high leakage rates, even above 100 percent, which is possible where emissions per unit of production are higher in the unregulated countries receiving the leakage than in the regulated countries. ${ }^{96}$ Reports from specific sectors have indicated even higher leakage rates. ${ }^{97}$ Thus, partial

http://www.usatoday.com/weather/climate/globalwarming/

2007-04-24-china-emissions_N.htm (quoting IEA chief economist Fatih Birol's account of China's increased reliance on fossil fuels and its rapid increase in GHG emissions, now exceeding U.S. emissions).

95 See J. EDMONDS ET AL., Stabilizing $\mathrm{CO}_{2}$ Concentrations With INCOMPLETE INTERNATIONAL COOPERATION (2007). Note that the feasibility, emissions reductions, and costs depend on the date by which stabilization of atmospheric concentrations must occur, as well as on the concentration level of such stabilization. Edmonds et al. examine several different scenarios.

96 See Mustafa Babiker, Climate Change Policy, Market Structure, and Carbon Leakage, 65 J. INT'L ECON. 421, 421, 441 (2005) (finding "leakage rates as high as $130 \%$, in which case GHG control policies in the industrialized countries actually lead to higher global emissions").

${ }^{97}$ See Joseph Kahn \& Mark Landler, China Grabs West's Smoke-Spewing Factories, N.Y. TIMES, Dec. 21, 2007, at Al ("the same hulking blast furnace, dismantled and shipped piece by piece from Germany's old industrial heartland to Hebei Province, China's new Ruhr Valley. The transfer, one of dozens since the late $1990 \mathrm{~s}$, contributed to a burst in China's steel production, which now exceeds that of Germany, Japan and the United States combined. It left Germany 
action by some countries, yet omitting other major emitters (as in Kyoto), is at least partly undone by leakage and at worst could increase, not decrease, global emissions. ${ }^{98}$ Indeed, some of China's faster-than-forecast increase in emissions since about 1997 may be due to leakage from Europe and other countries limiting their GHG emissions after Kyoto.

Hence engaging China, India and other major developing countries is crucial to the environmental efficacy of a climate policy regime. Broad participation would also improve the functioning of a cap and trade system. It would widen the range of low-cost abatement opportunities and it would reduce the potential for exercise of market power by large allowance holders.

But countries also face incentives not to join a global regime. Reducing emissions incurs costs domestically and in the present, whereas the benefits of reduced emissions are shared globally and in the future. Thus each country has an incentive to free ride on others' abatement efforts. Further, fear of cross-border "leakage" compounds this incentive. And some countries may perceive benefits from warming, such as increased agricultural output.

Thus a successful climate change policy regime, at least one designed to limit GHG emissions, must engage countries in cooperative action by promising sufficient shared benefits, or side payments. Countries are only bound by treaties to which they consent, so the treaty regime must make consent attractive. As noted above (in the section on incentives) and as I have argued elsewhere, a cap and trade system is best equipped to keep costs low while offering side payments (in the form of headroom allowances) to attract major developing countries to participate. ${ }^{99}$

The international prospects for cooperation on climate policy are evolving. Although a substantially global regime is needed to protect the global environment, countries have diverse interests, so

with lost jobs and a bad case of postindustrial angst. . . . China's less efficient steel mills, and its greater reliance on coal, meant that it emitted three times as much carbon dioxide per ton of steel as German steel producers.") (emphasis added).

98 At the same time, technological innovation and diffusion to unregulated jurisdictions could counteract leakage to some degree. For a more detailed discussion of leakage see Jonathan B. Wiener, Think Globally, Act Globally: The Limits of Local Climate Policy, 155 U. Pa. L. Rev. 1961, 1967-73 (2007).

99 See ReCOnstructing Climate Policy, supra note 2; Wiener, Global Environmental Regulation, supra note 8. 
some mechanism is needed to make cooperation attractive to the countries significantly influencing the outcome. For major developing countries whose priority is development-and who view climate change as being of low importance or even as benign-this means that climate policy must support their development goals, not impose obstacles or costs to their development.

Moreover, in the coming decades, we may see a more multipolar geopolitical terrain with a larger club of "great. powers"- the United States, an organized Europe, a revived Russia, a surging China, India, Brazil, and perhaps a few othersin a new world order of multiplex relations, cooperating and jousting over trade, debt, national security, climate, and other issues. This may complicate the prospects for climate policy, but it may also offer new opportunities for issue linkage (i.e., in-kind side payments) to persuade countries to act together. And, a country's identity as an emerging great power may give it a sense of leadership that motivates action on world issues.

Within China, the perceived impacts of climate change (and hence perceived benefits of prevention) may also be growing. Recent studies suggest that shifting precipitation could lead to both drought and flooding in China. ${ }^{100}$ Climate disruptions could lead to political instability, worrying China's leadership, which has committed to a "scientific concept of development" to achieve a "harmonious society" that reduces inequity and pollution. ${ }^{101}$ And China's emergence as a great power could lead it to put greater weight on the adverse climate impacts felt by its G-77 comrades in India, Asia and Africa. Meanwhile, economic models show China as a major beneficiary of a global cap and trade regime. Thus, even though China has so far declined to engage in such a regime, ${ }^{102}$ it may be moving toward doing so-if the U.S. will

100 See Erda Lin \& Ji Zou, HM Treasury, Climate Change IMPACTS AND ITS ECONOMICS IN CHINA, (Aug. 28, 2006).

101 See Wiener, Climate Change Policy and Policy Change in China, supra note 63 , at 1818-21. For interesting historical patterns of climate change and dynastic change in China, see Gergana Yancheva et al., Influence of the intertropical convergence zone on the East Asian monsoon, 445 NATURE 74 (2007); David D. Zhang et al., Climate Change and War Frequency in Eastern China Over the Last Millennium, 35 HUM. ECOLOGY 403 (2007).

102 See ZhongXiang Zhang, Why Has China Not Embraced a Global Capand-Trade Regime?, 7 Climate Policy 166 (2007). 
too. ${ }^{103}$

At the national level, current U.S. law does not seem well suited to the scale of climate change. The U.S. ratified the FCCC, but did not ratify the Kyoto Protocol, and thus the U.S. is not party to an international agreement quantitatively limiting GHG emissions. A key reason for the U.S. decision not to ratify Kyoto was the fear of leakage to unregulated countries such as China and India; the U.S. Senate voted ninety-five to zero not to ratify such a treaty in 1997, ${ }^{104}$ and citing this rationale, President Clinton never submitted the Kyoto Protocol to the Senate. In 2001, President Bush withdrew the U.S. from Kyoto.

In turn, the U.S. currently lacks national legislation to limit GHG emissions. As noted above, the U.S. Supreme Court has recently held that the CAA provides EPA the authority to regulate GHG emissions, but the regulatory tools in the CAA are a mismatch for a globally mixing pollutant. EPA can adopt controls on new vehicles, fuels, and new stationary sources, but these will not quickly address the large quantity of existing stationary sources. For existing stationary sources, EPA must mainly rely on the two-step NAAQS process, and the states must try to limit their emissions to attain the NAAQS. Yet GHGs are globally mixing pollutants whose concentrations within each state depend on global, not local, emissions. Thus, no state could by itself attain a binding ambient standard for $\mathrm{CO}_{2}$; even were a state to stop the growth in its own emissions, the ambient level (determined globally) would only be marginally affected. ${ }^{105}$ Even if all U.S.

103 See Wiener, Climate Change Policy and Policy Change in China, supra note 63 (discussing six factors that may be moving China toward engagement on international GHG emissions limits); Ning Zeng et al., Climate Change-the Chinese Challenge, 319 SCIENCE 730 (2008) (suggesting China's potential openness to a GHG tax or other limitations policy that reduces coal use in China, if it can be designed to support China's economic development). In turn, in early 2008 , the top U.S. climate official of the Bush administration said the U.S. could join a quantitative cap and trade regime, if China and India would too. See James Kanter \& Andrew Revkin, Binding Emissions Treaty Still a Possibility, U.S. Says, N.Y. TIMES, Feb. 27, 2008, available at http://www.nytimes.com/2008/02/27/world/europe/27climate.html.

${ }_{104}$ Byrd-Hagel Resolution, S. Res. 98, 105th Cong. (1997). Subsequent Senate votes in 2003 and 2005 on the McCain-Lieberman Climate Stewardship Act received 44 and 38 votes, respectively, but still not a majority, nor the 60 votes needed to end debate in the Senate, nor the 67 needed to ratify a treaty.

105 This is true even assuming that the sources controlled or eliminated within one state do not relocate or "leak" to other places. If such leakage does occur, as 
states acted together, the effect on global emissions (and hence on global concentrations) would still be modest, unless other major emitting countries also acted. The NAAQS/SIP process was aimed at limiting exposure to locally controllable air pollutants (and even for these, the NAAQS/SIP approach has proved problematic for interstate transport of air pollutants); it seems a serious mismatch to try to apply it to a globally emitted and globally mixing pollutant.

If EPA is obliged to regulate GHGs from stationary sources under the current CAA, there might be a better way: rather than have all 50 states adopt futile SIPs, EPA could short-circuit this process by declaring the SIPs inadequate to reduce ambient concentrations, and promulgating a Federal Implementation Plan (FIP) along with its NAAQS. The FIP would control emissions nationally. It could employ a cap and trade system. Indeed EPA has done this before, such as under its Clean Air Interstate Rule, for which it invited states to join a FIP with a cap and trade system. The definition of a FIP in CAA section 302 includes market-based incentives as one option. EPA's promulgation of a national cap and trade FIP for GHGs would enable it to adopt a more coherent national policy, with a greater ability to attain a NAAQS, while also giving EPA and the President leverage to bargain over similar legislation pending in Congress. Indeed such a strategy, following the Supreme Court's decision in Massachusetts v. EPA and championed by the next President, could a be key way to "break the logjam" by forcing Congress to act on climate change.

Well-designed new climate legislation would therefore be superior to regulating GHG emissions under the existing CAA. Short of new national legislation and EPA action under the CAA, the current situation is surprising: several states are enacting their own GHG limitation policies. These include California (limiting motor vehicle emissions and stationary source emissions), the Western Climate Initiative (a group of states joining California), several states emulating California's motor vehicles standard (which they may do under a special provision of the CAA if EPA

at least some probably would, then the state's efforts to control its own ambient level of $\mathrm{CO}_{2}$ via controls on emissions within the state would be even more futile or counterproductive. 
eventually gives California a waiver of federal preemption of such a standard-recently denied by EPA, but the question will be litigated), RGGI (a group of northeastern states adopting a capand-trade system), and other states. This is surprising because each state faces disincentives: local costs to restrict its emissions; benefits spread globally and into the future rather than enjoyed within the state in the present; and fear of leakage. Indeed, leakage may mean that state and local efforts will yield very little or even negative net reduction in global emissions. There may also be legal obstacles to state-level action on GHG emissions (absent federal approval): states' efforts to prevent leakage may be blocked by the Dormant Commerce Clause of the U.S. Constitution, some state regulations may be preempted by federal law such as the CAA (at least for mobile sources), states' efforts to combine into regional initiatives might bump into the requirement of Congressional approval under Interstate Compacts Clause, and states' efforts to link up with countries or regions outside the U.S. may be blocked by the Dormant Foreign Affairs clause. ${ }^{106}$ By contrast, if the states could act as part of a federal national regime, in partnership with state efforts, then these obstacles could be overcome, leakage could be reduced, and the states could employ their own regulatory powers most effectively. ${ }^{107}$

Why might the states be acting? In addition to changes in voters' preferences to favor such action (despite its high in-state costs and low in-state benefits), and the political ambitions of individual state leaders, there might be other motivations related to policy entrepreneurship. States might be seeking to:

- learn how GHG emissions trading markets work in anticipation of a federal cap and trade program;

- spur technological innovations that they can then sell to others once a federal or international regime is established; or

- create a patchwork of inconsistent state policies that will

106 On the states' policies and potential obstacles, see Wiener, Think Globally, Act Globally, supra note 98.

107 See the op-ed along these lines by the Massachusetts secretary of energy and environmental affairs. Ian Bowles, Want to Buy Some Pollution?, N.Y. TIMES, March 15, 2008, available at http://www.nytimes.com/2008/03/15/ opinion/15bowles.html. 
spur industry to lobby for a uniform federal policy. ${ }^{108}$

Yet such state actions may be counterproductive, by inducing leakage (as discussed above), and by creating a patchwork of inconsistent state policies that persist and become difficult to mesh into a coherent federal policy. ${ }^{109}$

Compared to the current scattershot of state-level initiatives with little federal action on GHG emissions, a better U.S. policy would involve at least three levels of scale:

$>$ At the global level, the U.S. should engage China, Europe, Russia, Japan, India, Indonesia, Brazil, Australia, Canada, Mexico, Korea, South Africa, and other major countries in a new regime to limit global GHG emissions (either as part of the post-2012 Kyoto Protocol, or as a parallel regime in a plurilateral approach), using international emissions trading and a comprehensive multi-gas, -sector, -source and sink design. ${ }^{10}$ This global-scale should be sought during 2009, the year the Bali Action Plan calls for a new post-Kyoto regime to be determined, with "measurable, reportable and verifiable" mitigation commitments by all countries. ${ }^{111}$

$>$ At the national level, the U.S. should enact similarly designed legislation in 2009 , the first year of the next Presidency, creating a cap and trade market in GHG emissions allowances, covering all GHGs, sectors, sources and sinks, and enabling U.S. actors to buy and sell emissions allowances internationally. This would give EPA a new task: tracking, monitoring and enforcing an allowance trading market similar to but potentially larger than the one created to control acid rain in 1990 (but a task much less onerous, to EPA and society, than if EPA were to set prescriptive technical standards for GHG emissions in each of numerous industries). In turn, to make way for this new responsibility, EPA should assign some of its current responsibilities to the states.

$>$ At the state level, the current state GHG policies (such as

108 See Wiener, Think Globally, Act Globally, supra note 98; DeShazo \& Freeman, supra note 9.

109 See Wiener, Think Globally, Act Globally, supra note 98.

110 This approach is detailed in RECOnStructing Climate Policy, supra note 2 .

111 Bali Action Plan, supra note 6. 
RGGI and the Western States program) should be folded into the new national and international cap-and-trade program. Some key climate policy tools, such as electric utility regulation, building codes, transportation systems, and land use planning, are handled by the states. The new national climate policy should encourage the use of such state and local authorities to reduce GHG emissions, so long as they do not impede the national cap-and-trade program. ${ }^{12}$ Meanwhile, as the federal government takes on the new task of running the GHG emissions limitation policy, issues such as standards for drinking water quality, air toxics, hazardous waste sites, and other issues posing local impacts, should generally be handled by the states rather than by the federal government (although the federal government could still play a role where there are economies of scale warranting a central national approach, such as in conducting risk assessments, some policy analyses, and technology $R \& D$ and evaluation, and in providing a clearinghouse to disseminate information and ideas across states).

This realignment of policies would address each problem at its appropriate scale.

\section{CONCLUSION}

We have learned much over the past four decades about the design of environmental policy, and we should apply this learning to climate change. This article advocates a policy design for climate change that succeeds on the four key design criteria: integration, tradeoffs, incentives, and scale. It advocates a comprehensive (multi-gas, sources and sinks, economy-wide), incentive-based (cap-and-trade) approach with allowances mostly auctioned and partly used to mollify serious opposition, and appropriate mechanisms to contain both cost and emissions escalation. This system would incorporate consideration of

112 See Bowles, supra note 107. Incorporating these state-level policies into a broader federal and global regime would help avoid leakage. A key issue is whether the federal law would preempt state policies. See ACSA, the Lieberman-Warner bill, supra note 13, would not preempt; indeed it would encourage states to adopt more stringent policies. 
relevant tradeoffs (risk-risk and benefit-cost), and would chart a long-term schedule of multi-year caps set by Congress and subject to periodic adjustment by with input from an expert body (such as EPA, or OMB, or a new "Carbon Fed") as new information warrants. It would be adopted at the appropriate scale: an international regime that effectively engages all major emitters, including the U.S. and China, coupled with national and subnational implementation.

A new climate change policy should learn from past experience with environmental law. It should match its scope to the extent of the externality, thus encompassing all sectors, GHGs, sources and sinks, in the U.S. and in other major emitting countries. It should address risk-risk and benefit-cost tradeoffs in a candid and transparent way. And it should take advantage of the cost savings, innovation and participation-attracting advantages of market-based incentive instruments.

These strategies may help "break the logjam" by launching the next major environmental legislation, on climate change. Putting a price on GHG emissions, if well-designed, will radiate throughout the economy, influencing myriad decisions in ways that protect the climate, reduce local pollution, and improve land use choices. A sound U.S. climate policy may also radiate internationally, serving as an example to be emulated by other countries. And the effects of good climate policy may radiate further, nudging or forcing reform of past U.S. environmental law, by showing the merits of superior approaches, and by putting pressure on existing institutions to reorganize in the face of their new responsibilities for climate policy.

That task is daunting enough, but it may be larger still. Constructing a truly effective global climate regime will be a strategic question of great power relations. Anticipating a coming era of a more multipolar world order, the year 2009 may come to resemble the year 1815 , when Metternich ${ }^{113}$ designed the multipolar regime to keep peace in Europe for a century. To break the global logjam, to engage China and thereby engage the U.S., to

113 See HENRY KISSINGER, A WORLD RESTORED: METTERNICH, Castlereagh, AND THE Problems of Peace, 1812-1822 (1957) (describing Metternich's diplomatic efforts, after the end of the Napoleonic Wars, to construct a flexible multipolar system that would deter war among the great powers of Europe). 
link smart domestic legislation with international cooperation, to apply the best understanding of regulatory design in concert with the best appreciation of national interests and global dynamics, in a way that safeguards the planet while fostering prosperity and equity, will require no less than a modern Metternich. 